\title{
A Climatology of Arabian Sea Cyclonic Storms
}

\author{
Amato T. Evan \\ Department of Environmental Sciences, University of Virginia, Charlottesville, Virginia \\ SUZANA J. CAMARGO \\ Lamont-Doherty Earth Observatory, The Earth Institute at Columbia University, Palisades, New York
}

(Manuscript received 8 January 2010, in final form 25 August 2010)

\begin{abstract}
On average 1-2 tropical cyclones form over the Arabian Sea each year, and few of these storms are intense enough to be classified as very severe or super cyclonic storms. As such, few studies have explicitly identified the seasonal to interannual changes in environmental conditions that are associated with Arabian Sea tropical cyclogenesis. However, over the last $30 \mathrm{yr}$ several intense Arabian storms did form and make landfall, with large impacts, which motivates this new study of the basin. The conclusions of earlier studies are visited by utilizing modern observational and reanalysis data to identify the large-scale features associated with Arabian tropical cyclone variability on seasonal time scales. Then year-to-year changes in environmental conditions that are related to interannual variability in Arabian storms during the pre- and postmonsoon periods are elucidated. The analysis of the relationship between large-scale environmental variables and seasonal storm frequency supports conclusions from work completed more than $40 \mathrm{yr}$ prior. Investigation of the year-to-year changes in premonsoon storm frequency suggests that May (June) storms are associated with an early (late) onset of the southwest monsoon. The findings also demonstrate that November cyclones (the month when the majority of postmonsoon cyclogenesis occurs) primarily form during periods when the Bay of Bengal experiences a broad region of high sea level pressure, implying that November storms form in either the Arabian Sea or the Bay of Bengal but not in both during the same year. Finally, the analysis of changes in a genesis potential index suggests that long-term variability in the potential for a storm to form is dictated by changes in midlevel moisture.
\end{abstract}

\section{Introduction}

Although only a couple Arabian Sea cyclonic storms form each year, occasionally a very powerful storm will make landfall. The strongest storm in the recent record was super cyclonic storm Gonu, which formed in early June 2007 and made landfall in both Oman and Iran. Gonu caused an estimated $\$ 4$ billion (U.S. dollars) in damages and collectively 100 deaths in Oman, United Arab Emirates, and Iran (JTWC 2007). To date, Gonu is the closest any cyclone on record had come to actually entering the Persian Gulf. One of the most destructive Arabian Sea storms, in terms of loss of human life, was very severe cyclonic storm $03 \mathrm{~A}$, which made landfall in the western Indian state of Gujarat in 1998 with a

Corresponding author address: Amato T. Evan, Department of Environmental Sciences, University of Virginia, 291 McCormick Road, Charlottesville, VA 22904.

E-mail: ate9c@virginia.edu maximum sustained wind speed of $105 \mathrm{kt}\left(54 \mathrm{~m} \mathrm{~s}^{-1}\right)$. More than 1100 deaths were attributed to this storm, many of which were reported to be workers in salt mines that were not evacuated prior to landfall (JTWC 1998). Although the damage from Gonu and very severe cyclonic storm $03 \mathrm{~A}$ was intense, landfall of seemingly innocuous storms can present opportunity for devastating losses. For example, in October 2008 deep depression 02A made landfall in Yemen with a sustained wind speed of only $25 \mathrm{kt}\left(13 \mathrm{~m} \mathrm{~s}^{-1}\right)$. Despite the weak nature of the storm, there was report of widespread flooding, 22000 displaced people, 180 deaths, and $\$ 1$ billion in damages (WHO 2009).

Because the northern Indian Ocean as a whole has relatively few cyclonic storms in a given year (Lander and Guard 1998), there are few publications related to climate and tropical cyclones (TCs) here and even fewer that explicitly consider storms that form over the Arabian Sea. Gray (1968) performed a comprehensive summary of global tropical cyclone activity and the conditions that 
forced observed seasonality of cyclogenesis in every basin. With regard to storms forming over the Arabian, Gray (1968) identified the bimodal seasonal cycle of Arabian storm frequency and attributed the depression of July and August cyclogenesis to strong vertical shear in the presence of intense upper-level easterlies and the seasonal displacement of the monsoon trough over the Indian subcontinent. Gray otherwise noted that Arabian storms tended to form during the spring northward advancement or fall southward withdraw of the monsoon trough, and that vertical shear values were favorable poleward of the trough when the trough's meridional position was between $5^{\circ}$ and $10^{\circ} \mathrm{N}$.

Recently Camargo et al. (2010) summarized more recent findings on tropical cyclones and climate globally, and here we discuss the subset of Arabian Sea tropical cyclones in slightly more detail. Lee et al. (1989) examined environmental characteristics surrounding severe cyclonic storm 02A, which formed over the Arabian Sea in June 1979. Lee et al. (1989) identified a series of eastward frontal systems that appear to strengthen the Somali jet and extend its low-level flow eastward across the Arabian. This intensification of low-level westerlies enhanced the cyclonic circulation of a preexisting disturbance that was just poleward of the jet axis, which, when combined with the development of sufficient upper-level outflow channels, provided the needed conditions for storm organization and genesis. Camargo et al. (2009) used fields of the so-called genesis potential (GP) index in conjunction with the Wheeler and Hendon (2004) MaddenJulian oscillation (MJO) index to determine the role of the MJO in global cyclogenesis. Camargo et al. (2009) demonstrated that enhanced values of the GP index over the northern Indian Ocean during August-October (ASO) for the active phases of the MJO over the Indian Ocean were associated with increases in midlevel moisture and low-level vorticity. However, given the bimodal distribution of Arabian Sea storms, diagnosis of the relationship between Arabian storms and the MJO would be made more relevant by instead considering the periods of May-June and October-November. Using cyclone data from a storm atlas published by the India Meteorological Department (IMD) for the period 1877-1989, Singh et al. (2000) found neither long-term linear trends in seasonal Arabian Sea cyclonic storm frequency nor a statistically significant correlation with the Southern Oscillation index. However, the quality of this historical data is not discussed, and therefore it is impossible to evaluate the robustness of the Singh et al. (2000) results without further details on the data sources and shortcomings.

In this manuscript we use Joint Typhoon Warning Center (JTWC) best-track data in conjunction with observational records and reanalysis data to identify coherent large-scale conditions associated with Arabian Sea tropical cyclone frequency on seasonal to interannual time scales. Our goal is to revisit earlier findings regarding the seasonality of Arabian storms (i.e., Gray 1968) and to identify environmental conditions associated with observed year-to-year changes in Arabian cyclogenesis. The remainder of this article is organized as follows: Section 2 describes data used in this study; section 3 presents a recent climatology of Arabian storm frequency and intensity; section 4 discusses intraseasonal cyclonic storm variability in terms of large-scale environmental features; section 5 examines the environmental conditions associated with year-to-year changes in Arabian cyclones; and section 6 uses the genesis potential index as another method to understand intra- and interannual Arabian cyclonic storm variability. Section 7 concludes the paper with a summary of the findings and a discussion of other factors not considered here that may be important to understanding Arabian Sea cyclonic storm frequency and intensity.

\section{Data}

Here we consider Arabian Sea tropical cyclones over the period of 1979-2008 using position and intensity estimates reported in the JTWC best-track dataset (Chu et al. 2002). Although JTWC annual tropical cyclone reports (ATCRs) began to include storm summaries for the Arabian Sea in 1972, JTWC best-track data for the Arabian are likely to be of good quality post-1978, since it is after this date that the ATCRs and best-track records consistently agree on the number of tropical cyclones that formed in the basin (Chu et al. 2002). Intensity estimates are reported as the maximum 1-min sustained wind speed at 10-m height in knots and are made using the Dvorak model (Dvorak 1975, 1982, 1984, 1995). As such the quality of these intensity estimates may be low (Chu et al. 2002).

At the time of writing the International Best Track Archive for Climate Stewardship (IBTrACS) (Knapp et al. 2010) included best-track data from the IMD for the Arabian over the period of 1991-2008. Agreement in identification of a tropical cyclone for the IMD and JTWC data (both from the IBTrACS) was high. In general, disagreement only occurred for cases when the JTWC identified very weak and short-lived storms whose maximum wind speeds peaked just above $34 \mathrm{kt}$ for one or two 6-hourly periods, which were not identified in the IMD analysis. Intensity estimates from the JTWC and IMD did differ (both are also from IBTrACS), with the IMD estimates being consistently 5-10 kt lower than those from JTWC. However, this may be the result of 


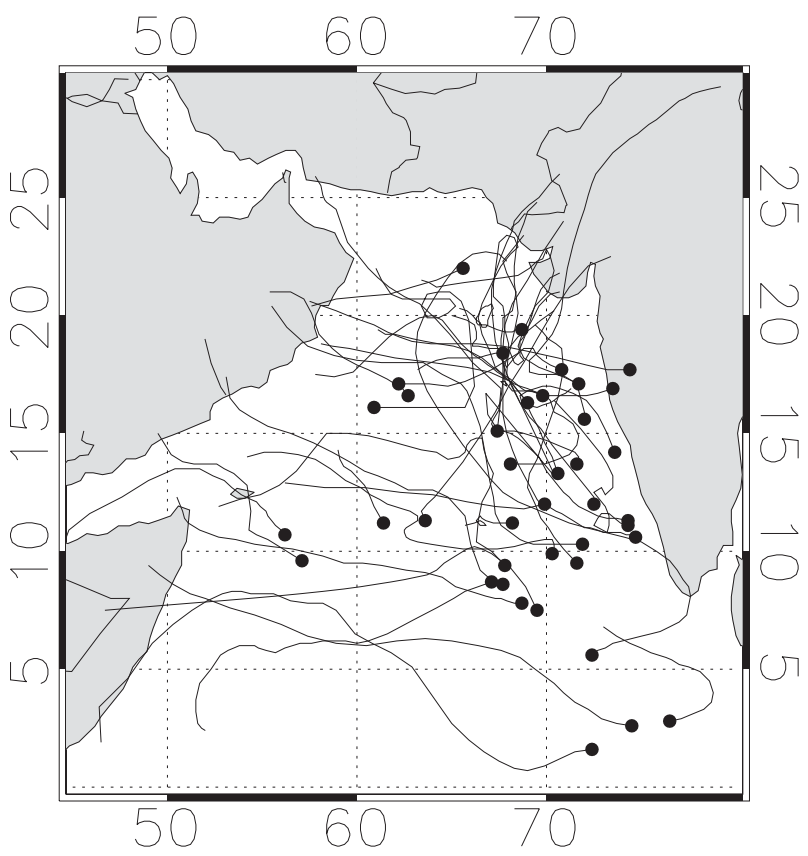

FIG. 1. Map of the Arabian Sea cyclonic storm tracks for the period 1979-2008. Filled circles represent the genesis points for each storm. Only storms with genesis in the Arabian Sea are included here.

comparing 1-min JTWC and 3-min IMD wind speeds (Knapp et al. 2010). Because we are interested in longterm changes in Arabian cyclone activity, here we only use position and intensity data from the JTWC archive.

For our analysis of large-scale conditions associated with Arabian cyclogenesis, we employ reanalysis fields from the National Centers for Environmental PredictionNational Center for Atmospheric Research (NCEPNCAR) Global Reanalysis 1 (Kalnay et al. 1996) and sea surface temperature (SST) data from both the Met Office Hadley Centre Sea Ice and Sea Surface Temperature dataset (HadISST) (Rayner et al. 2003) and the National Oceanic and Atmospheric Administration Optimum Interpolation Sea Surface Temperature (NOAA OISST) dataset for the genesis potential index calculations (Reynolds et al. 2002). Details of how the genesis potential index was derived and can be calculated are given in Camargo et al. (2007).

\section{Recent cyclonic storm activity}

We define an Arabian Sea cyclone as a storm whose best-track genesis occurs in the northern Indian Ocean and west of $77^{\circ} \mathrm{E}$. Most Arabian Sea cyclones form close to the western coast of the Indian subcontinent and follow a northerly or northeasterly track. Several storms have formed more toward the center of the basin or
TABLE 1. Classification convention for TCs over the Arabian Sea and the North Atlantic (and eastern Pacific). Winds for Arabian and Atlantic storms are reported as 1-min averages. Note that the Atlantic equivalent category for an Arabian storm is an approximation.

\begin{tabular}{|c|c|c|}
\hline $\begin{array}{c}\text { Wind } \\
\text { speed }(k t)\end{array}$ & $\begin{array}{l}\text { Arabian Sea } \\
\text { classification }\end{array}$ & $\begin{array}{l}\text { Approx Atlantic } \\
\text { equivalent }\end{array}$ \\
\hline $17-33$ & Tropical depre & Tropical d \\
\hline $34-47$ & Cyclonic storm & Named tropical storm \\
\hline $48-63$ & Severe cyclonic storm & Named tropical storm \\
\hline 64-119 & $\begin{array}{l}\text { Very severe } \\
\text { cyclonic storm }\end{array}$ & Hurricane categories $1-3$ \\
\hline$\geq 120$ & Super cyclonic storm & Hurricane categories 4 and 5 \\
\hline
\end{tabular}

closer to the equator and have taken a more easterly path (Fig. 1). Since the vast majority of recent publications on tropical cyclones and climate have focused on understanding activity in the Atlantic basin, it is useful to define the nomenclature used for Arabian Sea storms in terms of the Atlantic storm intensity classification system (Table 1).

Based on the JTWC best-track data for the period 1979-2008, 41 cyclonic storms formed in the Arabian Sea, of which 23 made landfall with tropical depression or stronger intensities. The average lifetime of these storms was 3.4 days, and the range of lifetimes is $1-9$ days. In this record 8 storms were classified as severe cyclonic storms, 7 were classified as very severe cyclonic storms, and 1 super cyclonic storm was recorded.

One metric of gauging storm frequency and duration is cyclonic storm days: the number of days that a tropical cyclone, whose lifetime maximum best-track wind speed is at least $35 \mathrm{kt}\left(17 \mathrm{~m} \mathrm{~s}^{-1}\right)$, is present in the basin. The annual distribution of monthly total cyclonic storm days over the Arabian Sea is bimodal, with peaks in activity occurring May-June and then October-December (MJOND), with decreased tropical cyclone activity during the peak of the Indian monsoon (Fig. 2; Gray 1968). Over the period of 1979-2008, there has been an average of 4.7 cyclonic storm days per year over the Arabian Sea, with 1981, 1990, 1991, 2000, 2005, 2008 having 0 storms; and 1998 and 2004 having more than 15 cyclonic storm days (Fig. 3). There is an apparent increase in cyclonic storm days over the period of 1992 2008 when compared to 1979-91. The mean annual cyclonic storm days for the earlier period is 2.3 , while the mean for the latter is 6.4. The difference of 4.1 cyclonic storm days between the two time spans is statistically significant at the $97 \%$ level based on the $t$ score of a twotailed Student's $t$ statistic on the two populations (as well as when using the Tukey Honestly Significant Difference Test based on our post hoc determination of the 1991 separation between the two periods). There were 


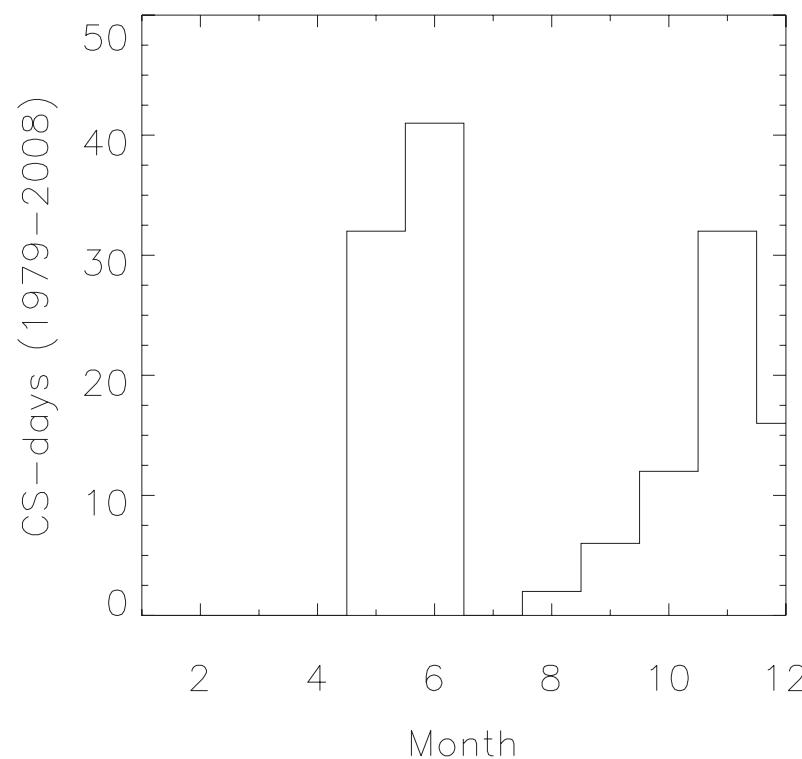

FIG. 2. Histogram of the number of cyclonic storm days, by month, for the period 1979-2008. See text for the definition of a cyclonic storm day. Only storms with genesis over the Arabian Sea are considered.

an average of 0.8 storms per year pre-1992 and 1.8 storms per year post-1992; however, the average storm lifetime remained more or less constant (3.0 and 3.7 days for the pre- and post-1992 dates, respectively). Therefore, the increase in cyclonic storm days is more reflective of an increase in storm frequency than duration. It is possible that this increase in cyclonic storm days is related to improvements in observational platforms or changes in operational guidelines (e.g., Landsea et al. 2006), and it is not possible to demonstrate that the increase in stormdays is physical without further analysis of the best-track data and its origin.

During the presouthwest monsoon period (May-June; Fig. 2), from one year to the next, storms generally occur either during May or June; however, they seldom occur consecutively in both (Fig. 3). We hypothesize this preference for one month over the other is a function of the southwest monsoon onset date, with an early onset favoring May storms and a late onset favoring June storms, a theory we develop further in section 3 that is consistent with Gray (1968). During the active months following the southwest monsoon withdrawal (September-December; Fig. 2), the division in activity between the pre- and post1991 periods is clear, with only 5 months registering some storm activity in the earlier epoch and 17 active months in the later epoch (Fig. 3).

Another useful metric for quantifying tropical cyclone activity is accumulated cyclone energy (ACE; Bell 2003), which is the sum of the square of a storm's maximum sustained 1-min wind speed. Since ACE is a summation

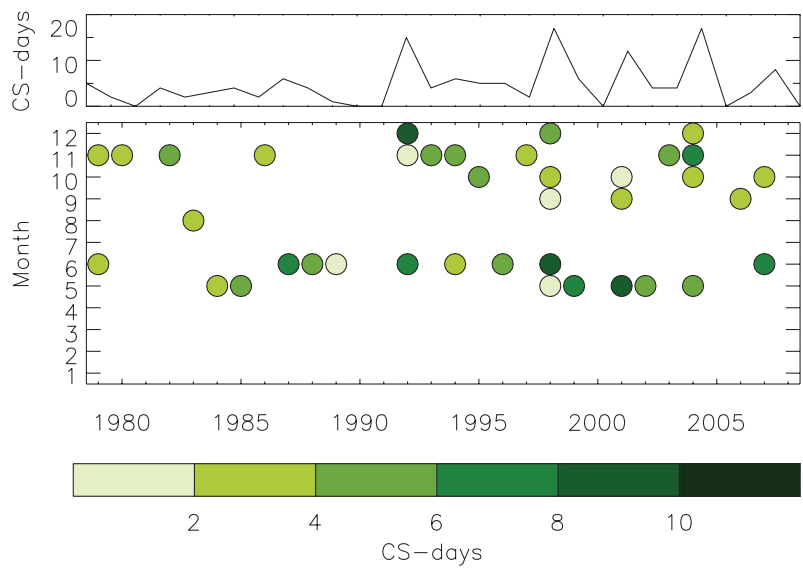

FIG. 3. (top) Annual time series and (bottom) monthly scatterplot of cyclonic storm days (CS-days) over the Arabian Sea for the period 1979-2008. In the (bottom) the number of days is indicated by the fill color of each circle.

over the lifetime over the storm, seasonal ACE values are a function of storm frequency, duration, and intensity. A monthly histogram of ACE for the period 1979-2008 shows that ACE for the premonsoon period is more than double that of the postmonsoon period (Fig. 4). Climatological total ACE for May and June is 40 and $47 \mathrm{kt}^{2}$, respectively, while the total ACE for November, the busiest month in the postmonsoon period, is $25 \mathrm{kt}^{2}$.

Similar to the time series of TC days, there are clearly two periods of storm activity in the annual ACE time series, although the division in the ACE series occurs $6 \mathrm{yr}$ after the TC days separation: 1979-97 and 19982008 (Fig. 5). Annual average ACE of the earlier period $\left(2.2 \mathrm{kt}^{2}\right)$ is roughly one-fourth the average annual ACE value of the later period $\left(8.2 \mathrm{kt}^{2}\right)$. While increases in cyclonic storm days over the last $30 \mathrm{yr}$ appear to be related to increases in storm-days during both the pre- and postsouthwest monsoon period (Fig. 3), the dramatic increase in annually averaged ACE is seemingly dominated by four premonsoon cyclonic storms (Fig. 5): very severe cyclonic storm TC 03A (June 1998), very severe cyclonic storm TC 02A (May 1999), very severe cyclonic storm TC 01A (May 2001), and super cyclonic storm Gonu (June 2007). However, the fact that ACE appears to dramatically increase at 1998 is suspect, since this is also the period in time when a Meteosat geostationary satellite that was positioned at $0^{\circ} \mathrm{E}$ longitude was repositioned to $63^{\circ} \mathrm{E}$, establishing 3-hourly IR and visible satellite observations directly over the Arabian Sea (e.g., Knapp and Kossin 2007). It is probable that an increase in satellite observations would lead to increased and earlier detection of weak storms, or it allow for changes in the JTWC 6-hourly intensity estimates (Landsea et al. 2006). Independent satellite intensity analysis suggests 


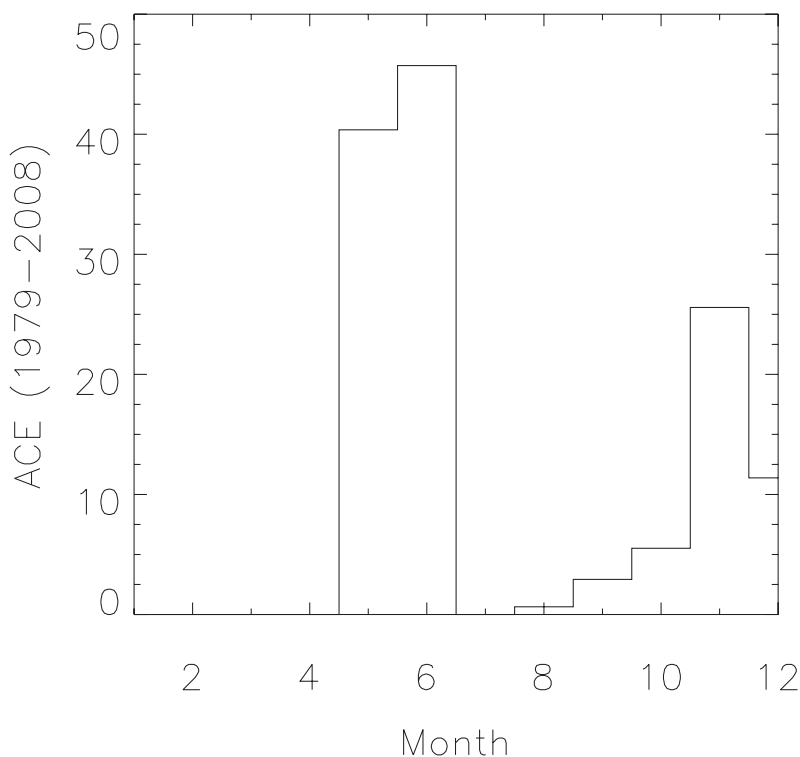

FIG. 4. Monthly histogram of ACE for the period 1979-2008. ACE is only calculated for storms having genesis points over the Arabian Sea and a maximum sustained wind speeds $>34 \mathrm{kt}$ $\left(17 \mathrm{~m} \mathrm{~s}^{-1}\right)$.

that seasonal intensity over the northern Indian Ocean is decreasing over time (Kossin et al. 2007); however, updates to the intensity estimate methodology that account for dramatic temporal changes in regional satellite coverage show an increase in the intensity of the strongest storms over the last quarter century (Elsner et al. 2008). Given the low confidence in the Arabian intensity estimates (Chu et al. 2002) without further data analysis, it is not yet possible to determine if any portion of the upward trend in Arabian Sea cyclones, as seen in the JTWC best track, are physical.

\section{Seasonal variability}

It is well known that the southwest monsoon circulation dominates the large-scale features of the Arabian Sea, and that no cyclonic storms develop over the Arabian while the monsoon trough is at its most northerly position and located over the Indian subcontinent (Fig. 2). Gray (1968) explored the environmental controls establishing the bimodal seasonal cycle of Arabian cyclogenesis. As mentioned earlier Gray (1968) found that pre- and postmonsoon storms occurred when the monsoon trough was located at $5^{\circ}-10^{\circ} \mathrm{N}$ latitude; however, he found that during the monsoon onset (July-August), copious vertical shear and displacement of the trough over the Indian subcontinent precluded intensification of any convective system. Gray (1968) also speculated that cool Arabian Sea surface temperatures associated

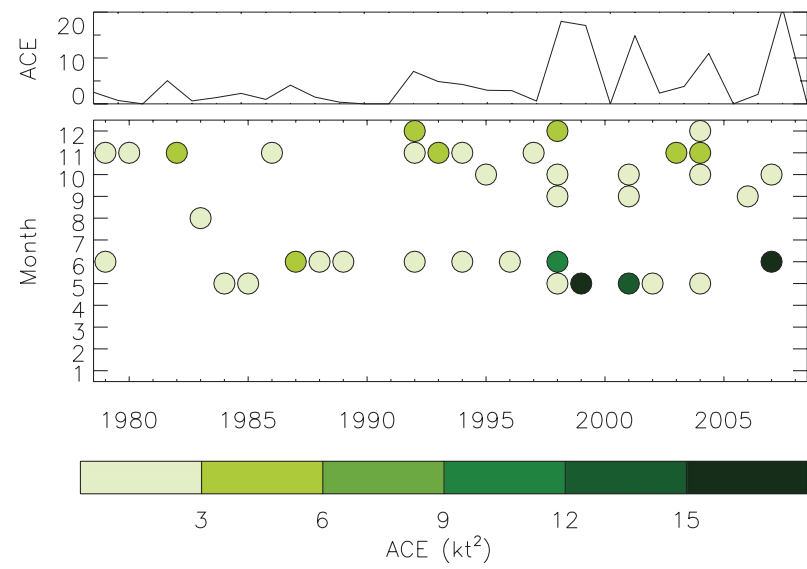

FIG. 5. As in Fig. 3, but for ACE.

with the monsoon onset would not have an important effect on storm genesis.

Here we revisit these 4-decade-old findings in more detail by analyzing the seasonal evolution of large-scale features relevant to cyclone genesis and intensification, namely sea surface temperature, upper- and lower-level convergence, wind speed and direction, vertical wind shear, low-level vorticity, and sea level pressure (SLP). While this is not an exhaustive list of environmental conditions that are important to understanding cyclone activity, at least for the Arabian Sea, these features do seem to well describe large-scale conditions as they relate to cyclone activity in this basin.

The large-scale dynamics of the southwest monsoon are described in numerous publications, and here we refer the reader to Hastenrath (1991, chapter 6) for a more detailed explanation of the circulation patterns described here. The southwest summer monsoon is associated with a low level southwesterly jet off the eastern coast of northern equatorial Africa (the Somali or East African jet), and a southerly cross-equatorial flow along the western Indian Ocean (Fig. 6). Surface wind stress associated with the jet forces an offshore Ekman flow, upwelling along the coast of East Africa and the Arabian Peninsula, and cooling of the Arabian Sea during the height of the monsoon period (Fig. 6).

Based on Hadley SST data spanning the period of 1979-2008, the forcing of Arabian sea surface temperatures by low-level winds is strongest during July and August and results in a bimodal annual distribution of regional SST, with maximums in May (absolute) and October (relative), and nearly equivalent minimums in January and July (Fig. 7). Climatologically, the jet and the southerly cross-equatorial flow begin to develop in May-June; the maximum in the lower-jet-level wind speeds and surface ocean cooling is during July-August; 

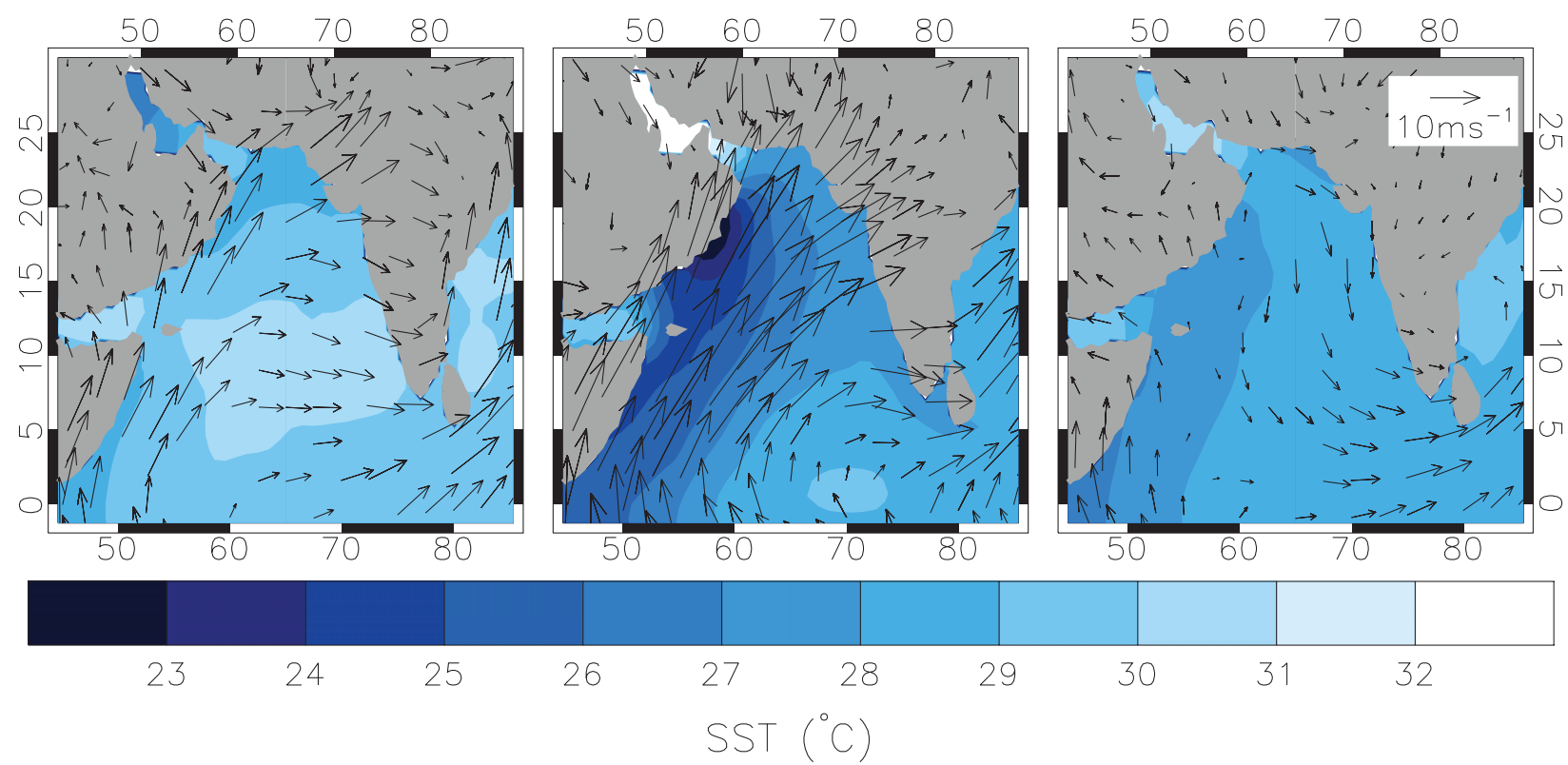

FIG. 6. Maps of monthly-mean SST (shaded) and 10-m winds (arrows) for the months of (left) May, (middle) August, and (left) October. The climatology period is 1979-2008.

and by October, the low-level circulation over much of the Arabian is northerly and the monsoon trough is displaced to near the equator (Fig. 6). Despite the strong wind-driven cooling along the western boundary of the Arabian Sea, ocean surface temperatures over many parts of the basin remain above $26.5^{\circ} \mathrm{C}$, an empirical threshold for cyclogenesis (Gray 1968), throughout the entire year (Fig. 6), and most storms form along the eastern boundary of the Arabian (Fig. 1), where surface temperatures are $1^{\circ}-4^{\circ} \mathrm{C}$ warmer than those of the basin's western sector (Fig. 6).

The Somali jet breaks eastward once it leaves the coast of eastern Africa, and this westerly branch of the jet has a latitudinal shift according to the season, with the jet position slightly north of the equator during the boreal spring, at a northerly maximum during JulyAugust, and then taking up a position near or south of the equator during the fall (Fig. 8). Large-scale low-level relative vorticity (here calculated as the $925-700-\mathrm{mb}$ layer-mean vorticity) is stratified about the westerly branch of the Somali jet, with negative vorticity equatorward and positive vorticity poleward of the jet's axis. Cyclongenesis consistently occurs poleward of the jet's monthly climatological axis (Fig. 8) (Gray 1968). To some degree the annual cycle of the position and intensity of the jet, coupled with the cool ocean surface temperatures that result from wind-driven upwelling along the eastern coast of Africa, explain the pattern of cyclogenesis from one month to the next over the Arabian. For example, during the months of July and
August, the jet is at its most poleward position and the only regions where climatological low-level vorticity values are favorable for cyclogenesis (Fig. 8) are also those areas where ocean temperatures are cool because of wind-driven upwelling and temperature advection (Fig. 6). During the pre- and postmonsoon periods of May-June and October-November, respectively, the

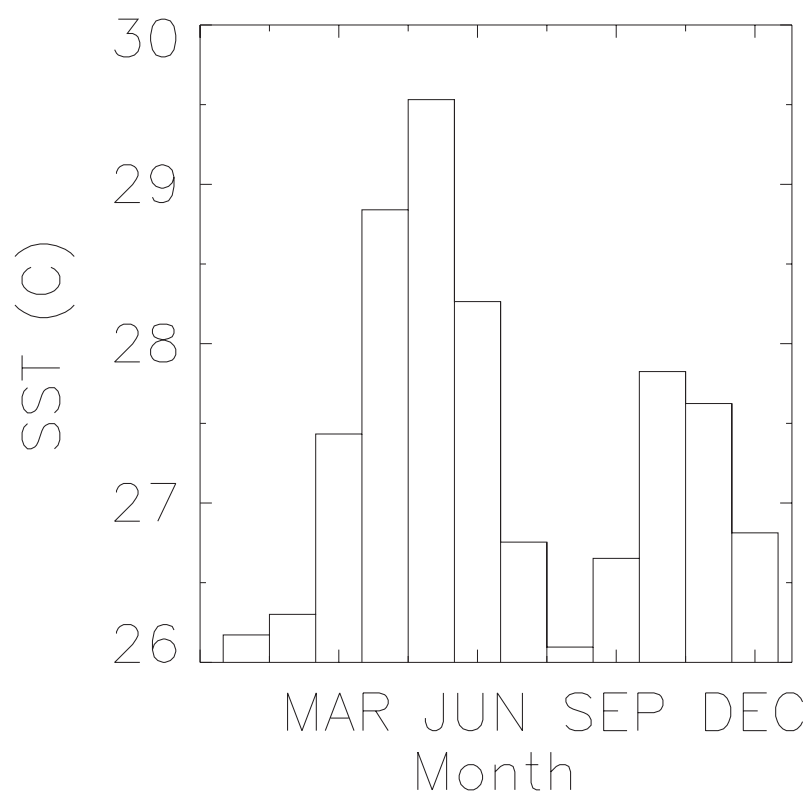

FIG. 7. Annual cycle of monthly-mean Arabian Sea SST $\left({ }^{\circ} \mathrm{C}\right.$; $7.5^{\circ}-20^{\circ} \mathrm{N}, 50^{\circ}-80^{\circ} \mathrm{E}$ ) for the period $1979-2008$. 

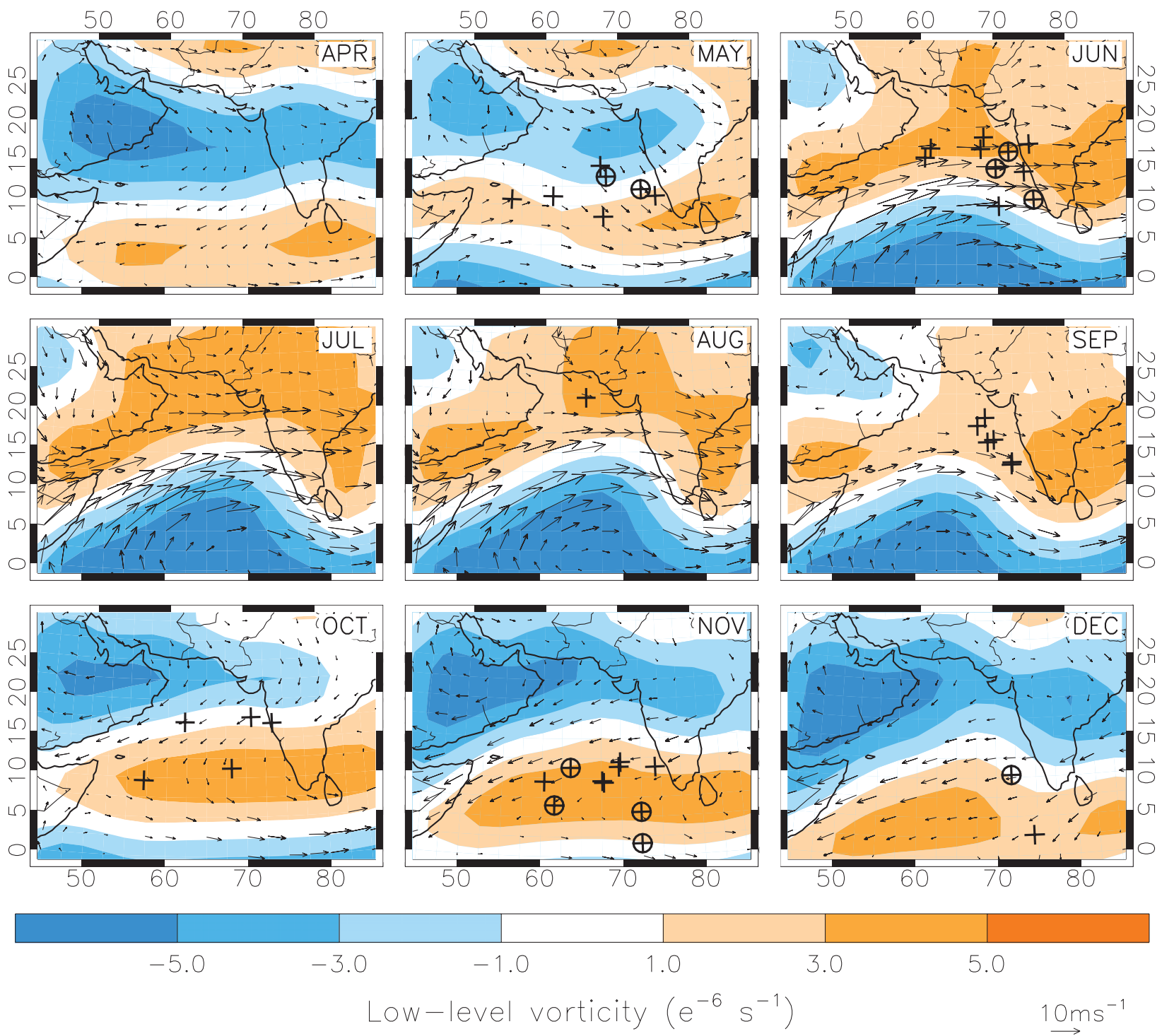

FIG. 8. Maps of monthly-mean low-level relative vorticity (shaded) and 850-hPa vector winds (arrows). TC genesis locations for each month are denoted by a cross, and storms that reached a maximum 1-min sustained wind speed of $\left.64 \mathrm{kt} \mathrm{(33} \mathrm{m} \mathrm{s}{ }^{-1}\right)$ are indicated by a circle at the genesis location. Climatology period for vorticity, winds, and cyclogenesis is 1979-2008.

equatorial position of the jet and broad region of positive vorticity values (Fig. 8) that are coupled with warmer regional ocean temperatures (Fig. 6) provide a larger favorable region for storm development.

The genesis points of Arabian Sea cyclones, position of the Somali jet, and pattern of Arabian Sea SST are clearly related (Fig. 8). However, the Arabian Sea also exhibits an annual cycle of vertical wind shear that is very relevant to understanding the seasonal pattern of cyclone development (layer vertical shear is defined as the difference between the 200-150- and 925-700-hPa layers, calculated using 6-hourly reanalysis data over the period of 1979-2008; Gray 1968). Over the Arabian Sea, vertical shear largely follows the magnitude and direction of the $200-\mathrm{hPa}$ wind: during the late fall, winter (not shown), and early spring months, the upper tropospheric flow poleward of $10^{\circ} \mathrm{N}$ is dominated by the subtropical westerly jet; and upper-level flow during the summer months is similarly controlled by the tropical easterly jet, which develops in late spring and has a maximum in magnitude during July-August (Fig. 9). Climatological vertical shear values are between 5 and $10 \mathrm{~m} \mathrm{~s}^{-1}$ in the regions where cyclone genesis events have been recorded for the months of May, October, and November (Fig. 9), suggesting that during these months, cyclone formations are not necessarily shear limited. As 

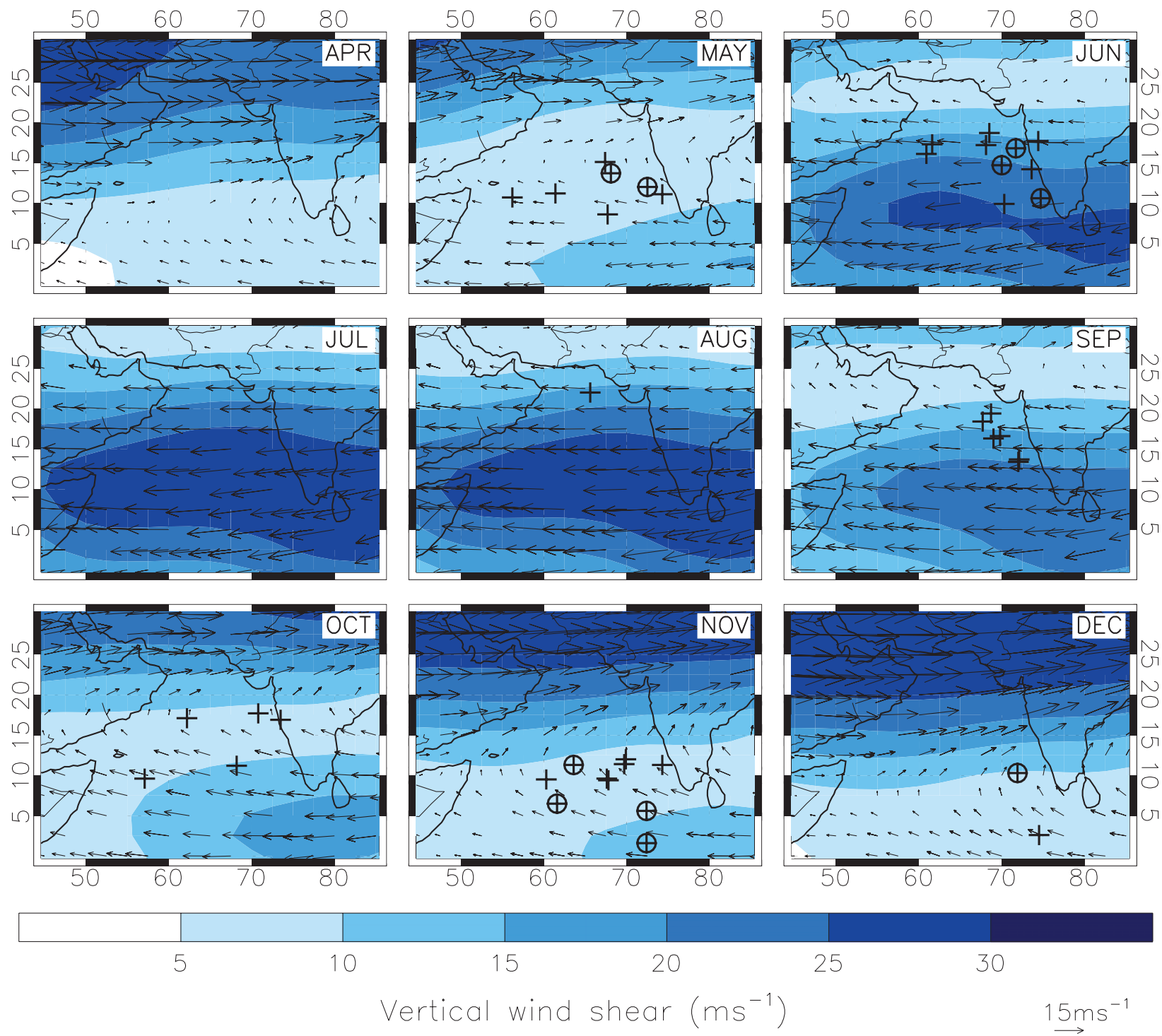

FIG. 9. As in Fig. 8, but for monthly-mean vertical wind shear (shaded) and 200-hPa vector winds (arrows).

discussed earlier, during these months the relatively low shear values are also accompanied by positive low-level vorticity (Fig. 8) and warm SST (Fig. 6). Cyclogenesis during the months of June and September occurred in regions where long-term mean shear values were 10 $25 \mathrm{~m} \mathrm{~s}^{-1}$ (Fig. 9), implying that storms forming during the summer months, when the tropical easterly jet is a maximum in magnitude, are likely to be shear limited.

\section{Interannual variability}

Although Arabian Sea cyclogenesis has been noted in May-June and August-December, most storms (70\%), and nearly all $(90 \%)$ of the very severe and super cyclonic storms, form during the months of May, June, and
November. Therefore, it is instructive to examine how conditions during these months differed when cyclogenesis is active (with TCs) and inactive (without TCs) seasons. To do this we analyze the reanalysis fields composited on storm counts. We define anomalous conditions associated with storm genesis to be the difference between the mean fields for months when tropical cyclogenesis did occur and the mean fields for months when no storm genesis took place. Statistical significance is attributed to the composite differences using a two-tailed Student's $t$ test and a $90 \%$ significance of difference threshold.

While it is unlikely that monthly-mean reanalysis fields are influenced sufficiently by the short-lived Arabian storms to bias our composites, as this possibility was 

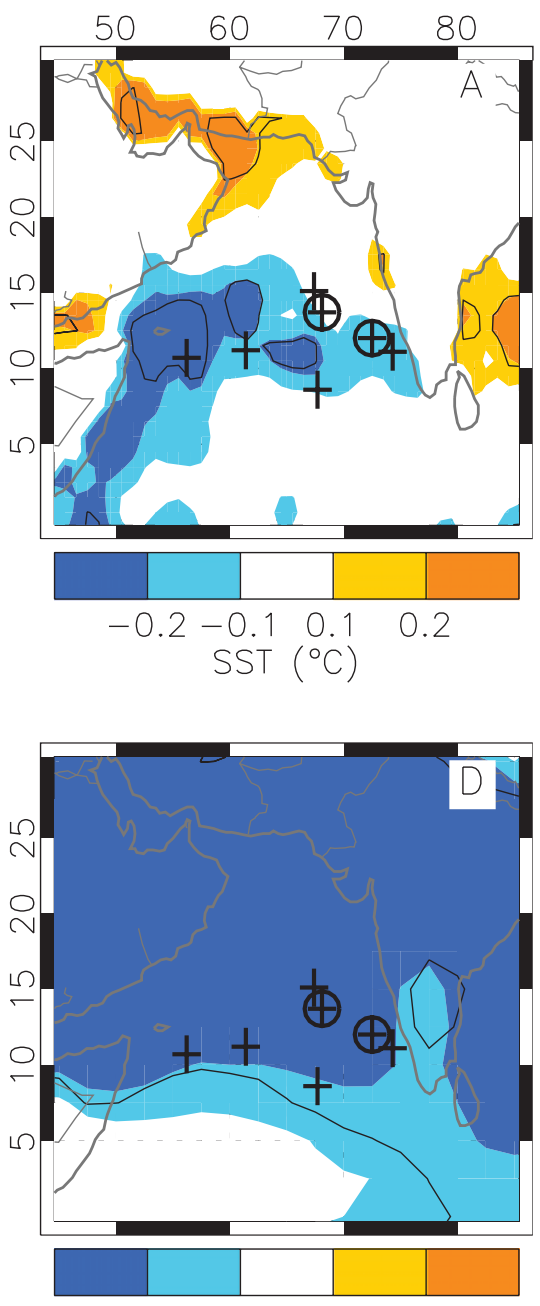

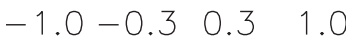

SLP $(m b)$

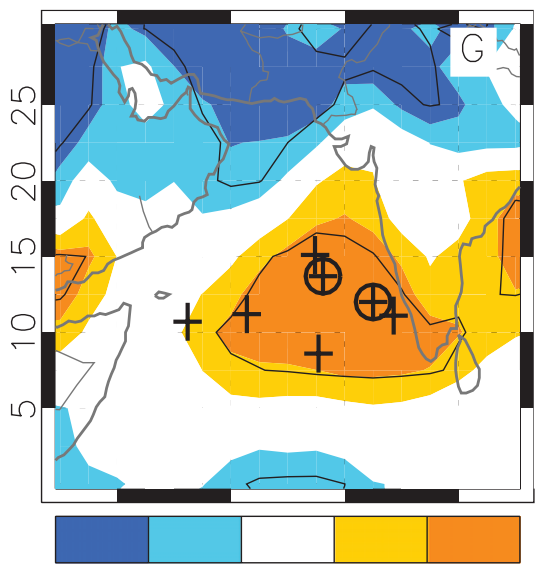

$\begin{array}{llll}-5.0 & -2.0 & 2.0 & 5.0\end{array}$

$600 \mathrm{hPa}$ rel. humidity (\%)
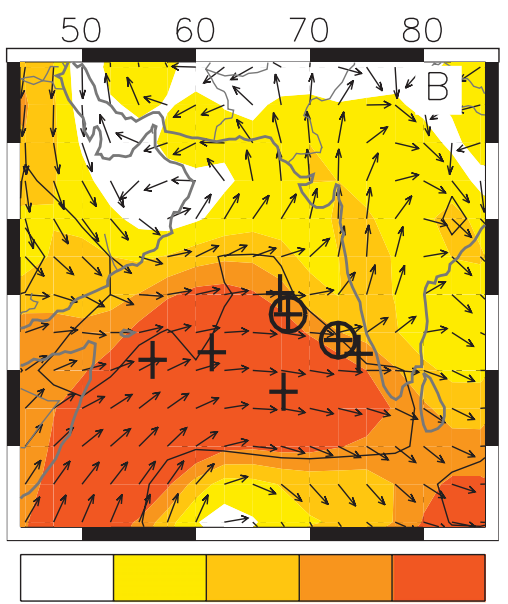

$\begin{array}{llll}0.5 & 1.0 & 1.5 & 2.0\end{array}$

$850 \mathrm{hPa}$ Wind $\left(\mathrm{ms}^{-1}\right)$

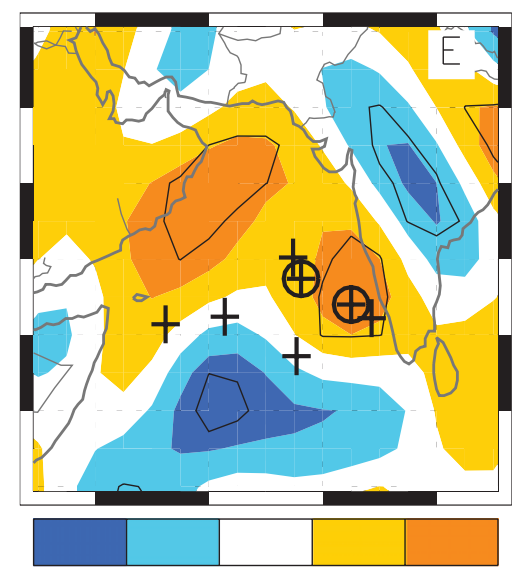

$\begin{array}{llll}-3.0-1.0 & 1.0 & 3.0\end{array}$

Low Level Vort $\left(\mathrm{e}^{-6} \mathrm{~s}^{-1}\right)$

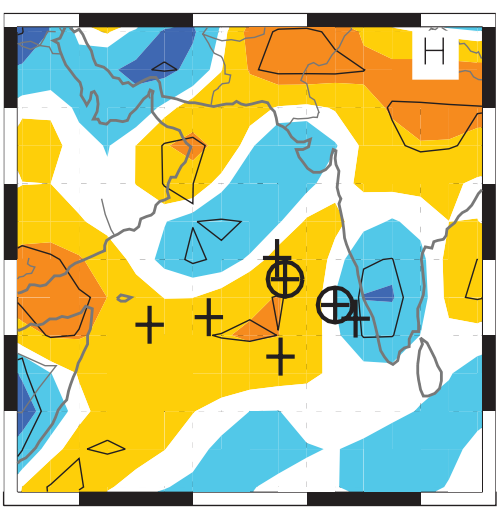

$\begin{array}{lll}-1.0-0.2 & 0.2 & 1.0\end{array}$

850 hPa Conv. $\left(e^{-6} s^{-1}\right)$
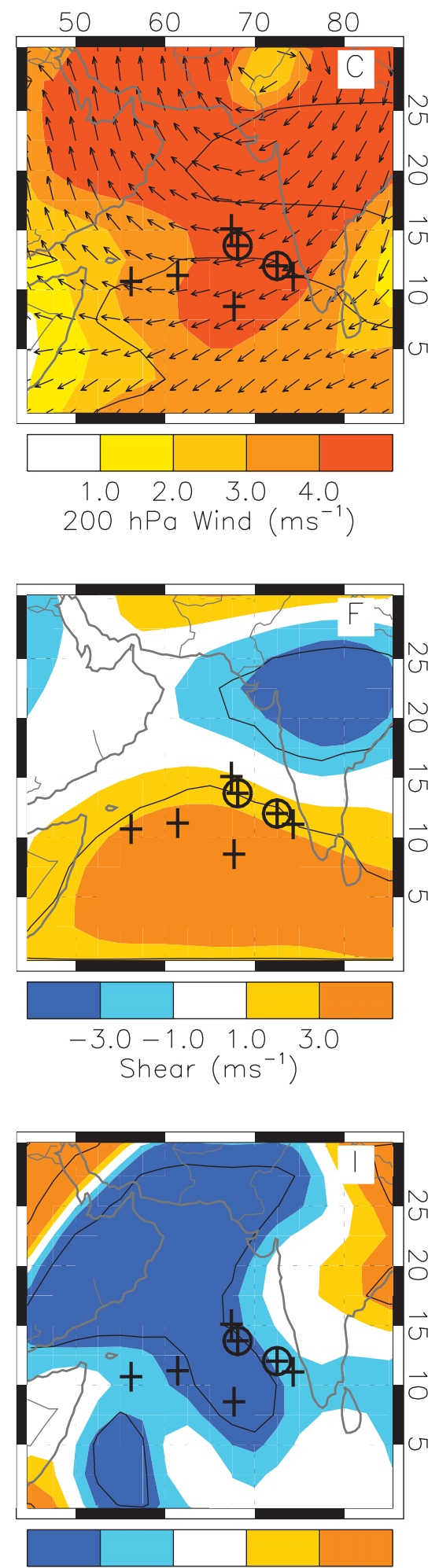

$\begin{array}{llll}-1.0 & -0.4 & 0.4 & 1.0\end{array}$

$200 \mathrm{hPa}$ Conv. $\left(\mathrm{e}^{-6} \mathrm{~s}^{-1}\right)$ 
discussed in Swanson (2008), we briefly examined this issue. We considered the differences of June 2007 monthlymean fields of the reanalysis variables with another June 2007 mean constructed without including data from those days when super cyclonic storm Gonu was present in the basin. Not surprisingly, there was no noticeable change in the monthly-mean fields that can be attributed to the passage of this storm (not shown).

For the case of cyclonic storms in May, statistically significant anomalous conditions include cooler ocean surface temperatures off the Somali coast that extend eastward at $10^{\circ} \mathrm{N}$, low SLP, an enhanced Somali jet and positive vorticity north of the jet axis, a developing tropical easterly jet with an upper-level anticyclone centered over northwestern India, increased vertical wind shear south of $15^{\circ} \mathrm{N}$, increased midlevel moisture, and broad upper-level divergence (Fig. 10). These anomalous conditions are similar to those present during the southwest summer monsoon; anomalous onshore low-level flow along the western coast of the Indian subcontinent, which forces cooler ocean surface temperatures, is coincident with a tropical easterly jet work together to increase the local vertical shear (Figs. 6, 8, and 9). Thusly, conditions are favorable for May storms to form when there is an early monsoon onset. Interestingly, May cyclogenesis is more favorable when ocean temperatures are anomalously cool and the magnitude of vertical shear is anomalously large (Fig. 10).

In many ways anomalous conditions for June storm genesis are opposite of those for May cyclogenesis. June storms are associated with an enhanced Somali jet with a more equatorial position and offshore low-level flow along the Indian subcontinent, anomalous upper-level westerlies, low SLP across much of the basin, and an increase in vorticity in the region of genesis (Fig. 11). These conditions are consistent with the patterns of upper- and lower-level winds before the monsoon onset (Figs. 8 and 9), thus implying that June genesis is associated with a late onset of the southwest monsoon. Although weaker vertical shear and increased midlevel moisture are also present when June storms form, the differences are not statistically significant, and lower and upper-level convergence fields are not organized well enough as to suggest important differences in large-scale vertical motion.

During the month of November, enhanced cyclonic storm activity is not as clearly associated with a typical monsoon circulation. Low-level equatorial easterlies, an upper-level ridge over the northern Indian subcontinent, and high SLP over the Bay of Bengal conspire to force regional low-level convergence and upper-level divergence in the November genesis region (Fig. 12). In addition, midlevel relative humidity is anomalously high across much of the Arabian (Fig. 12), which is coincident with negative anomalies of outgoing longwave radiation (not shown). There is nearly no anomalous change in vertical shear or surface temperature in the genesis region, and no statistically significant anomalies of lowlevel vorticity and SLP are associated with November cyclogenesis (Fig. 12).

As high SLP over the Bay of Bengal is coincident with Arabian Sea cyclogenesis for the month of November (Fig. 12), there is the interesting possibility that when conditions are favorable over the Arabian Sea for storms to form, they are not over the Bay of Bengal. This is born out in composites of outgoing longwave radiation, which show positive anomalies over the Bay of Bengal when composited on Arabian Sea storms. From 1979 to 2008, 9 Arabian Sea and 14 Bay of Bengal tropical cyclones formed. During 21 years of the 19792008 period, 1 storm formed in either the Arabian Sea or the Bay of Bengal, no storms formed at all during 8 of these years, and during only 1 yr (1986) did a storm form in both basins (Table 2). This 1986 Bay of Bengal storm formed far to the north and had a lifetime of only $18 \mathrm{~h}$.

To test if this shift of November cyclogenesis to either the Arabian Sea or the Bay of Bengal observed in the best-track data is statistically significant, we randomly reassigned the years during which genesis occurred for the 14 Bay of Bengal storms and the 9 Arabian Sea storms and then counted the number of years an overlap of storms (1 Arabian and 1 Bay of Bengal during the same November) would occur over the 30 -yr span. This was repeated 10000 times, and a distribution of the number of years a storm formed in both basins was

FIG. 10. Anomalous large-scale features associated with May Arabian cyclonic storm genesis. Maps represent the differences between means of months that did and did not contain a cyclonic storm. Statistical significance at the $90 \%$ level is based on a $t$ score from a twotailed $t$ test of the separation of the means from the two distributions at each grid cell and is indicated by a solid black contour. Features considered here are (a) SST, (b) 850- and (c) 200-hPa winds, (d) SLP, (e) low-level layer-mean vorticity, (f) layer-mean vertical shear, (g) 600-hPa relative humidity, and (h) 850 - and (i) 200-hPa convergence. Cyclone genesis points are indicated by a cross, and storms that reached a wind speed of $64 \mathrm{kt}$ or greater during their lifetime are indicated by a circle. Period for the composites is 1979-2008. 
constructed from the results. From the cumulative distribution function of this distribution, less than $0.4 \%$ of the simulations resulted in a distribution analogous to that in the observations, where a storm formed in both basins during only one year (the average was 4.5 years that had November storms occur in both basins). Therefore, we suggest that the lack of overlap between November storms seen in the best-track data is statistically significant at the $99 \%$ level and is consistent with our composite analysis. Future work will be aimed at identifying the physical mechanisms that force this preference for November genesis in one basin or another.

Thus far our analysis has focused on various climatological conditions as they relate to monthly storm activity, and it has neglected explicit considerations of stability. The following section addresses the role of atmospheric stability in conjunction with vertical shear, low-level vorticity, midlevel humidity, and ocean surface temperatures by analysis of the so-called genesis potential index.

\section{Analysis of the GP index}

The GP index is an empirically derived index used to characterize the suitability of local environmental conditions for cyclone genesis (Emanuel and Nolan 2004), and an in-depth description of the GP index and its constituents can be found in Camargo et al. (2007). Briefly, the GP index as used here is defined as

$$
\mathrm{GP}=\left|10^{5} \eta\right|^{3 / 2}\left(\frac{f}{50}\right)^{3}\left(\frac{V_{\mathrm{pot}}}{70}\right)^{3}\left(1+0.1 V_{\text {shear }}\right)^{-2},
$$

where $\eta$ is the absolute vorticity at $850 \mathrm{hPa}\left(\mathrm{s}^{-1}\right), f$ is the relative humidity at $600 \mathrm{hPa}(\%), V_{\text {pot }}$ is the potential intensity (PI, $\mathrm{m} \mathrm{s}^{-1}$ ) (Emanuel 1988; Bister and Emanuel 2002a,b), and $V_{\text {shear }}$ is the magnitude of the vertical wind shear between 850 and $200 \mathrm{hPa}\left(\mathrm{m} \mathrm{s}^{-1}\right)$. Daily global GP fields are from the NCEP-NCAR Global Reanalysis 1 (Kalnay et al. 1996) and the NOAA OISST (Reynolds et al. 2002) dataset. The GP data have a horizontal resolution of $2.5^{\circ}$. We note that the absolute magnitude of any GP value is arbitrary and has no direct physical significance.

Regionally averaged monthly-mean GP index data can reproduce the annual cycle of cyclonic storms over the northern Indian Ocean (Camargo et al. 2007). In addition, the spatial pattern of climatological monthly GP index reflects the position of historical cyclone genesis points during each month of the tropical cyclone season (Fig. 13). Genesis generally occurs in regions where the climatological-mean GP index has high values, and GP is mostly low in those areas where no cyclone genesis has been observed (Fig. 13). In contrast, we also find two May and one October genesis points west of about $65^{\circ} \mathrm{E}$ in regions of climatologically low GP (Fig. 13).

Monthly GP index data also reflect the year-to-year changes in storm frequency. Differences in monthly GP index fields composited around storm genesis (similar to that described in more detail in section 4) all show positive GP anomalies for years during which a storm formed, and the spatial patterns of those anomalies well describe the best-track genesis positions (Fig. 14). In general genesis coincides with regions of positive GP anomalies, except for one May storm and one October storm that formed over the western sector of the Arabian Sea, and for one November storm and one December storm that formed very close to the equator. It is also interesting to note that November GP anomalies are less than zero over the Bay of Bengal when composited on Arabian Sea genesis (only the western part of the Bay of Bengal is shown, Fig. 14), further supporting the theory of an "either/or" basin preference for November storm formation.

We note that a similar composite analysis using PI instead did not show broad regions of positive potential intensity anomalies that were clearly associated with genesis locations. Hart et al. (2007) found a memory of 40-60 days in PI fields after the passage of a storm in the Atlantic and Pacific basins, and so we also examined the effect of TCs on local PI to determine if the storms themselves may be affecting our GP composite analysis. We repeated the methods of Hart et al. (2007) for all Arabian Sea storms during 1979-2008, but we instead found that on average the PI anomalies decay on an $e$-folding time scale of 5-7 days (not shown). Therefore, the possibility of the storms strongly affecting the GP composite analysis is very low.

One benefit of utilizing GP data is the ability to evaluate the temporal and spatial characteristics of basinwide storm activity independent of best-track data. We create a seasonal time series of Arabian GP that is an average of monthly GP values in the locations where historical cyclogenesis has occurred. This is in effect drawing a box around the locations where storms have formed in the past (this "box" changes from one month to the next) and then averaging the GP values in this area to calculate seasonal means. The time series of Arabian seasonal GP has a minimum in 1984 and a maximum in 1993 and exhibits a statistically significant upward trend (Fig. 15). From 1986 to 2003 seasonal GP varies with a very regular pattern of local minima $(1986,1991,1997)$ that are immediately followed by local maxima $(1987,1993,1999)$, then again minima (with values larger than the previous minima: 1989, 1995, 2001), and lastly another maxima (with values that are smaller than the previous maxima: 1990, 1996, 2002). This 

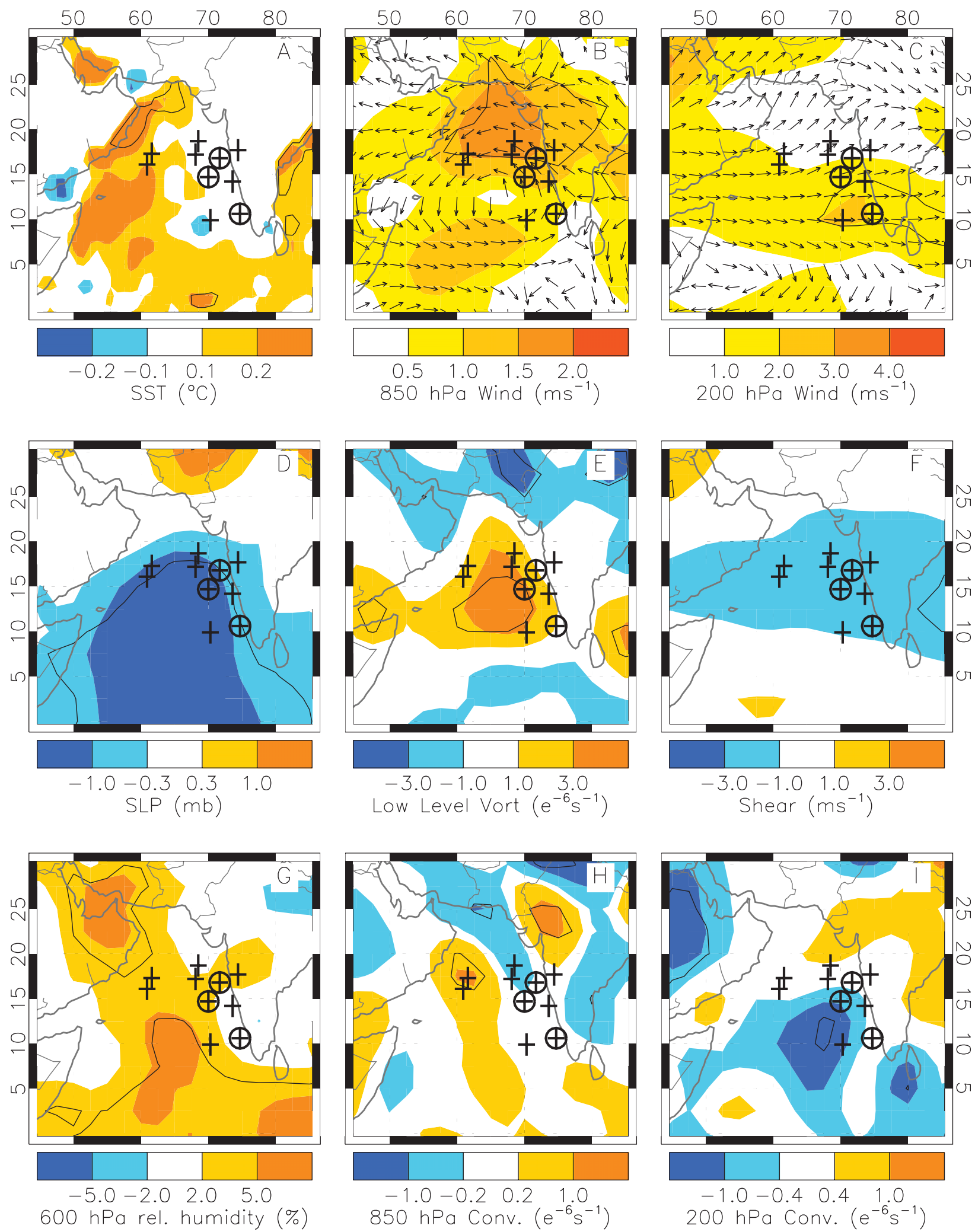

FIG. 11. As in Fig. 10, but for anomalous large-scale features associated with June Arabian cyclonic storm genesis. 

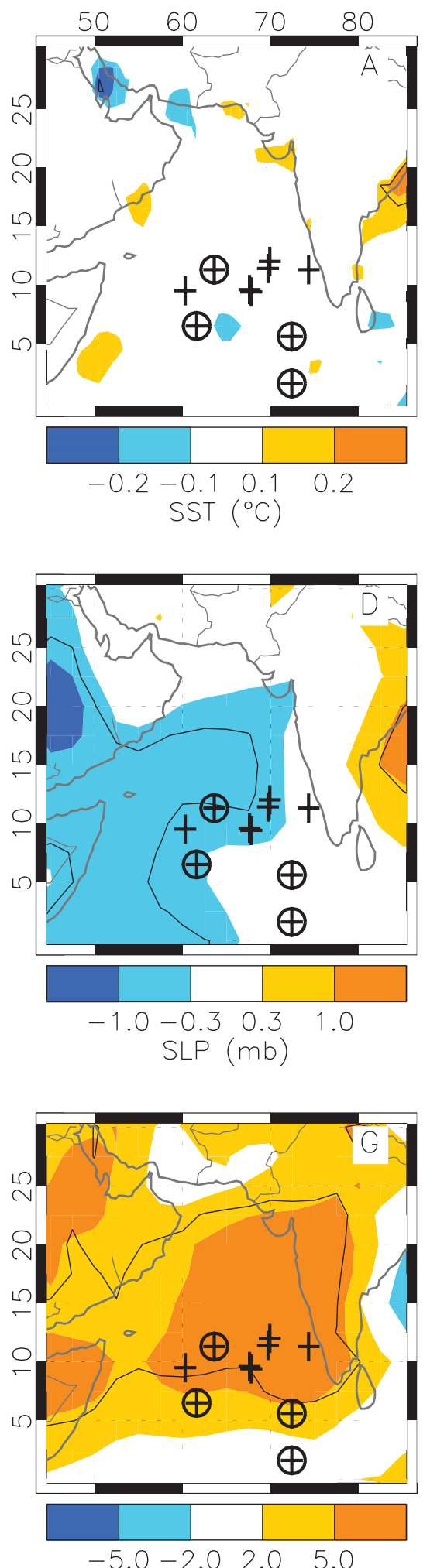

$600 \mathrm{hPa}$ rel. humidity (\%)

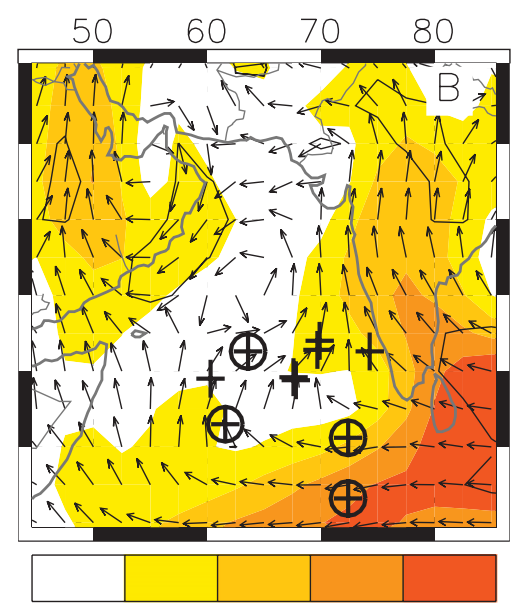

$\begin{array}{llll}0.5 & 1.0 & 1.5 & 2.0\end{array}$

$850 \mathrm{hPa}$ Wind $\left(\mathrm{ms}^{-1}\right)$
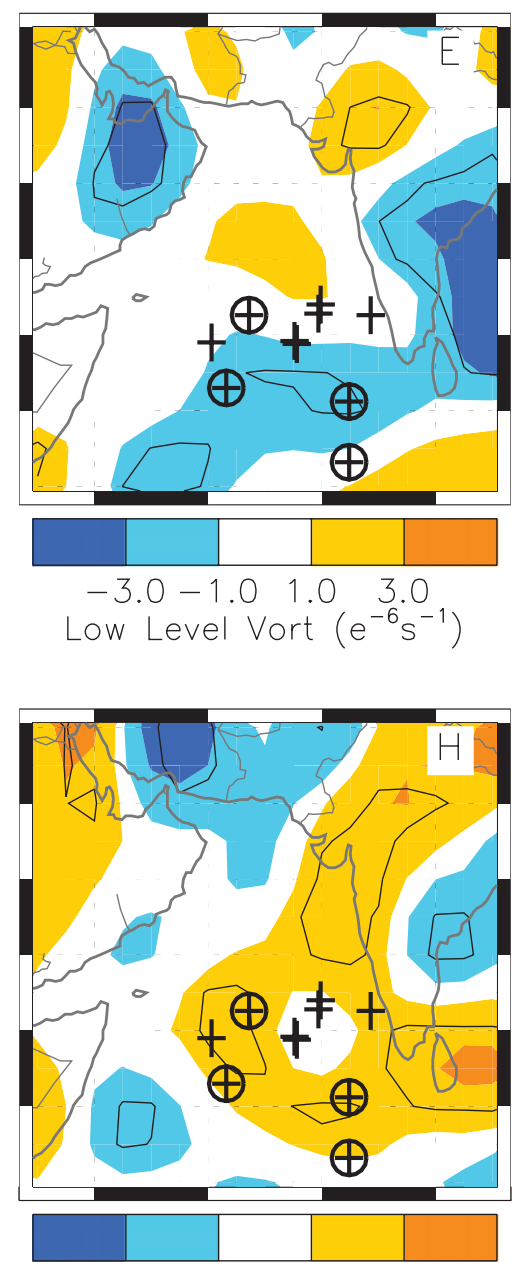

$\begin{array}{lll}-1.0-0.2 & 0.2 & 1.0\end{array}$

850 hPa Conv. $\left(e^{-6} s^{-1}\right)$
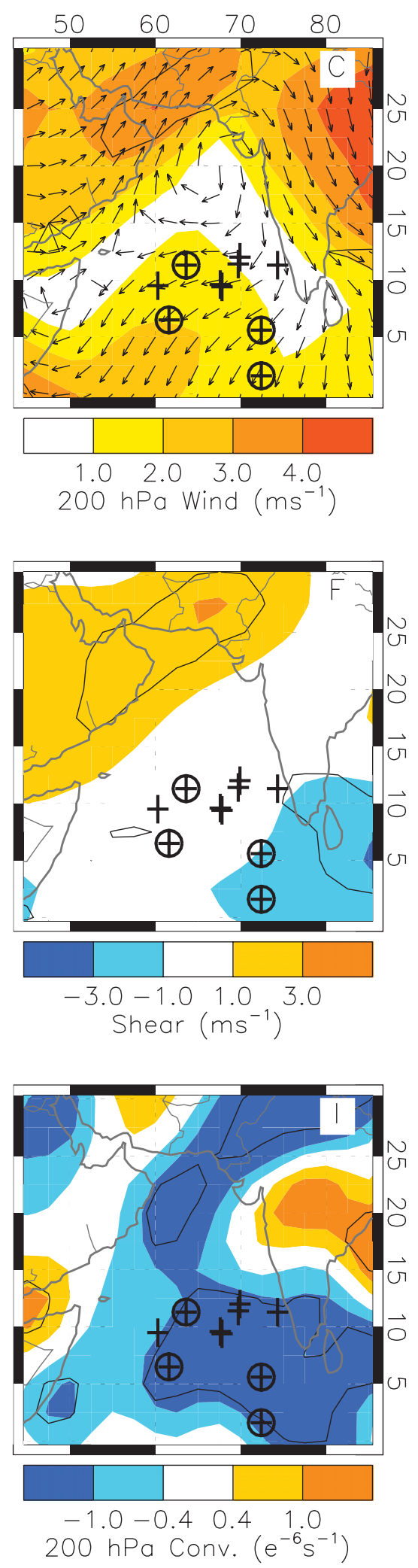

FIG. 12. As in Fig. 10, but for anomalous large-scale features associated with June Arabian cyclonic storm genesis. 
TABLE 2. Years during which November TCs formed over the Arabian Sea or the Bay of Bengal. The only year when a storm formed in both basins was 1986.

\begin{tabular}{lcc}
\hline & Arabian Sea & Bay of Bengal \\
\hline Storm years & $1979,1980,1982,1986,1993,1994,1997,2003,2004$ & $1981,1983-88,1992,1995,1998,2002,2005,2007,2008$
\end{tabular}

3- and 6-yr periodicity is odd, but we have not yet identified an artificial source of the repetition and for now should assume it is physical. A 1-4-6-4-1 low-pass filter of the seasonal GP time series shows the low frequency decrease in GP values from 1979 until 1985 and the subsequent increase in GP through 2008, as well as the 5-6-yr periodicity in the time series that persists from at least 1985 to 2008 (Fig. 15). The difference between mean GP values pre- and post-1992 (1.0 and 1.4, respectively) is statistically significant at the $99 \%$ level. Therefore, also considering the statistically significant upward trend, to some extent the GP data does support a physical interpretation of the increase in cyclonic storms days (Fig. 3), which we determined was largely due to increases in storm frequency rather than duration.

It is well known that Indian monsoon dynamics can be externally forced by ENSO (e.g., Shukla and Paolino 1983; Kumar et al. 2006), and it is possible that tropical
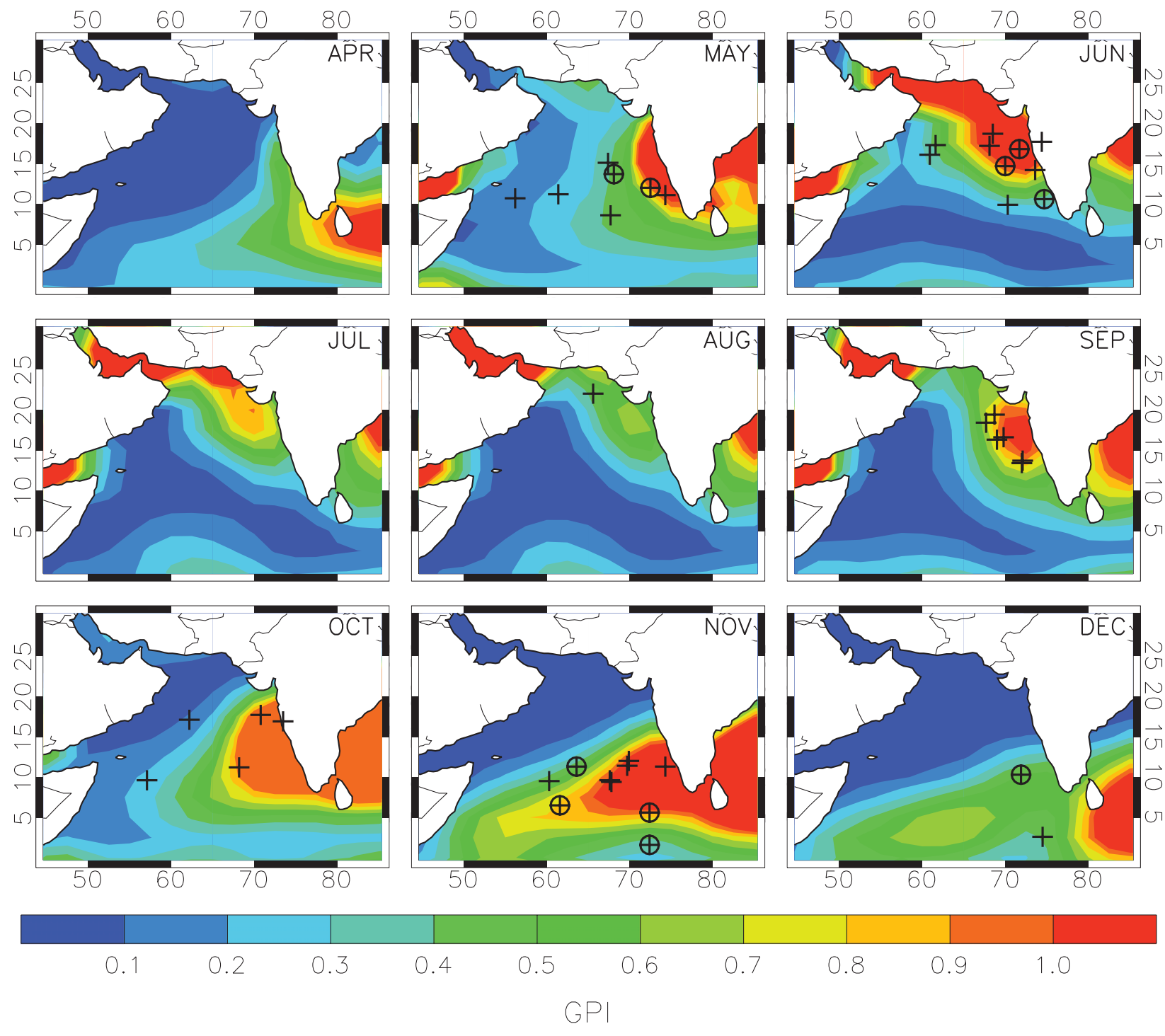

FIG. 13. Monthly-mean GP over the Arabian. GP climatology period is 1979-2008, and data are from daily reanalysis atmospheric and weekly SST fields. Note that genesis points are only plotted for storms that formed over the Arabian Sea. 

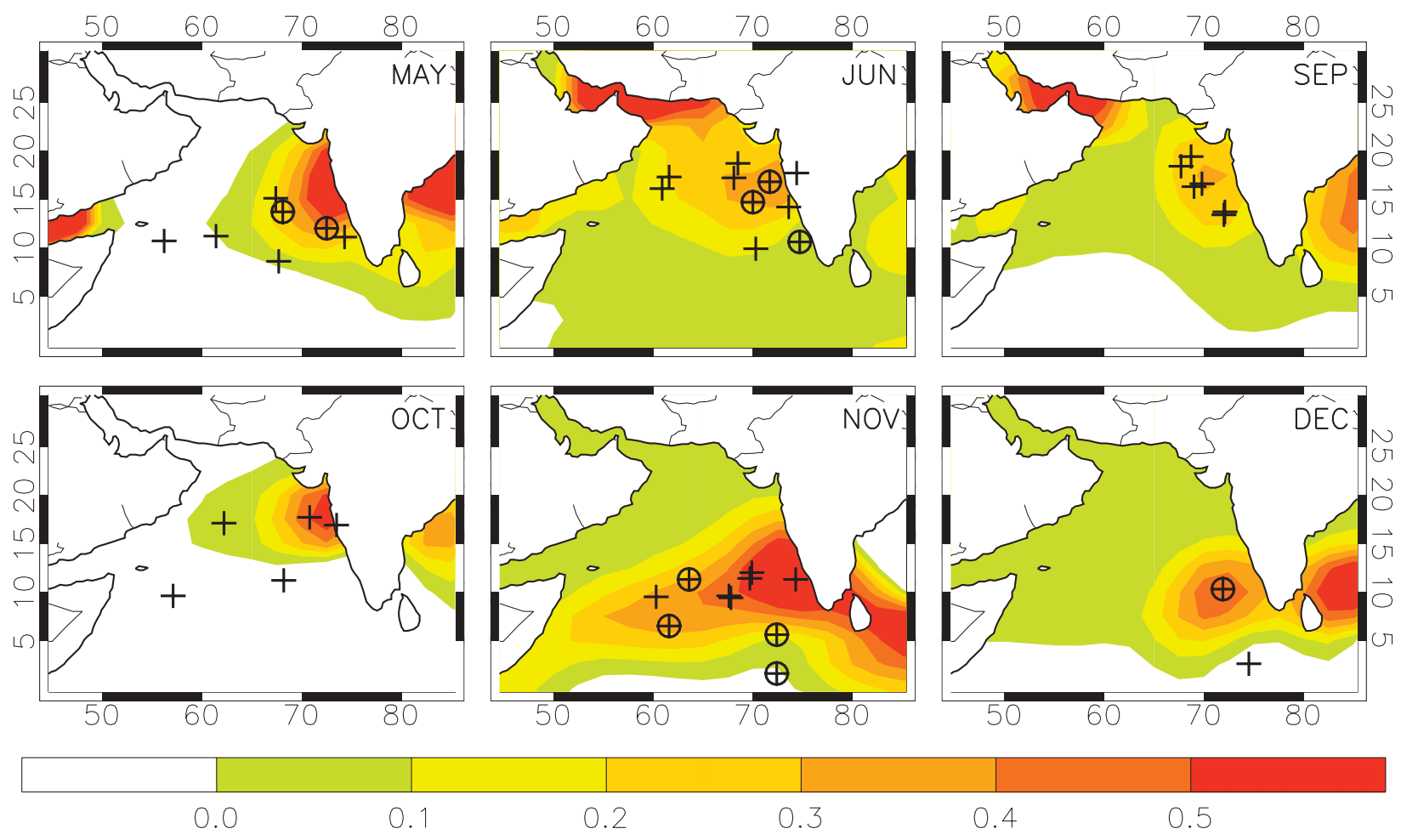

0.2

0.3

0.4

0.5

\section{GPI}

FIG. 14. Anomalous monthly-mean GP composites. Difference maps created by subtracting monthly-mean GP for months without storm activity from the mean for months that did contain at least one storm (1979-2008).

cyclone activity in the Arabian Sea is related to ENSO in the same way that monsoon rainfall is coupled to ENSO variability in the 2-7-yr time scales (Torrence and Webster 1999). Perhaps more relevant is that strong Niño events are often accompanied by a delayed monsoon onset (Joseph et al. 1994). However, we have not found a robust connection between metrics for storm activity and ENSO. For example, using a definition for an ENSO event similar to that of Trenberth (1997), mean seasonal (MJOND) cyclonic storm days and ACE values are not statistically different when separated by seasonal positive and negative ENSO events (95\% significance level). In addition, difference maps of mean monthly GP for different ENSO phases, created in a manner similar to that done in Fig. 14 and for the same months, do not show large and coherent regions of positive or negative GP anomalies over the Arabian (not shown). It is likely that the periodicity in the smoothed GP time series (Fig. 15) is at some level forced by ENSO. However, without a clear physical mechanism for determining how this relationship evolves over time, it is difficult to ascertain the relevance of ENSO to Arabian tropical cyclone activity without a more in-depth investigation, which is beyond the scope of this work.
In theory, reanalysis data are consistent over time, and therefore we are able to extend the Arabian Sea GP time series in Fig. 15 back to 1950 (Fig. 16). Over the last $60 \mathrm{yr}$, seasonal Arabian GP has exhibited large decadalscale swings; GP is above the long-term mean for much of the first half of the time series and below that mean during the second half of the record. The maximum in GP occurs in 1960 and the minimum in 1984, with nearmean values at the beginning and end of the record. Interestingly, the 30 -yr period we consider here is the minimum in GP, and therefore storm formation, over the last 60 yr (Fig. 16). Spectral analysis on the 59-yr GP time series (not shown) suggests that a 3-6-yr periodicity in GP that exists from the mid-1980s through 2000 (Fig. $15)$ is local to that period only and not a regular feature of the entire dataset.

It is possible that the GP time series suffers from some nonphysical artifact in the reanalysis data. One way to estimate, to first order, the validity of the GP data over these long time scales is to plot Arabian Sea storm counts from the JTWC best track over this same period. Keeping in mind that there is little confidence in the best-track storm counts pre-1978, the level of agreement between these two totally independent estimates of 


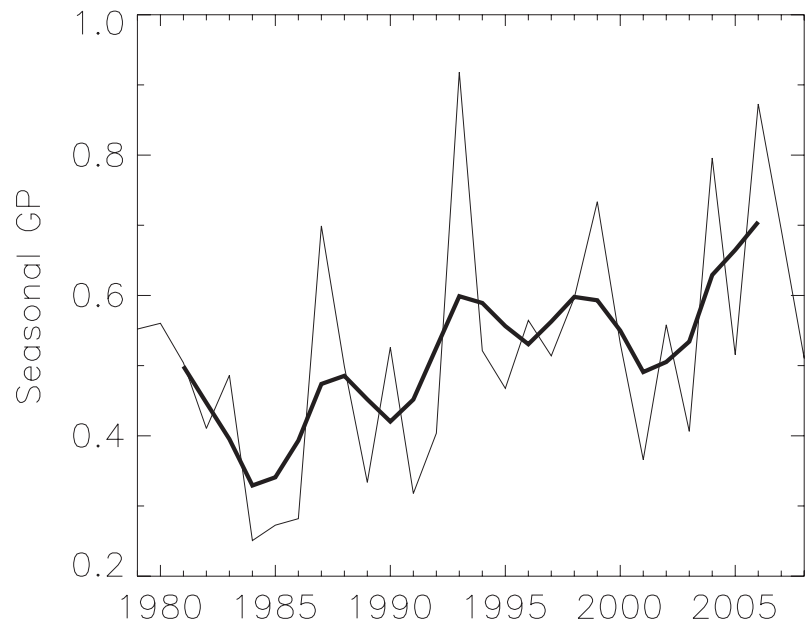

FIG. 15. Time series of seasonal Arabian Sea GP. The seasonal time series (thin line) is an average of GP data for the months of the Arabian cyclone season (May, June, and September-December) in the regions where historical cyclogenesis has occurred. The smoothed series (thick black line) is created by applying a 5-yr lowpass filter (1-4-6-4-1) to the seasonal series.

storm formation is surprising (Fig. 16). Besides the upswing in storm counts from 1970 to 1978 , the two lines follow the same decadal patterns, and the correlation coefficient between the two is 0.78 (60\% of the variance in one time series can be explained by the other). In addition, the nonfiltered annual time series of Arabian GP and JTWC storm counts is well correlated with an $R$ value of 0.62 (39\% of variance explained, not shown). Differences between the JTWC data and the GP for the 197078 could be due to error in the storm counts, a breakdown in the robustness of the GP formulation over this period, biases in the NCEP data, or a mix of all three.

To identify the factors that are forcing observed variability in the seasonal Arabian Sea GP time series (Fig. 16), and by association storm formation, we plot similarly constructed time series of SST, low-level vorticity, layer-mean vertical wind shear, and $600-\mathrm{hPa}$ relative humidity, as these are all input to the GP calculations (Fig. 17). The time series of SST is increasing over this period at a rate of $0.01^{\circ} \mathrm{C} \mathrm{yr}^{-1}$, similar to that reported by Clark et al. (2000), and the time series of relative humidity is decreasing at a rate of $0.13 \% \mathrm{yr}^{-1}$, while relative vorticity and vertical shear remain generally flat (Fig. 17). It is obvious that the smoothed relative humidity time series (Fig. 17) is most similar to the GP series (Fig. 16), and the two are correlated with an $R$ value of 0.90 ( $81 \%$ variance explained). The smoothed pattern of relative vorticity (Fig. 17) is also similar to that of GP (Fig. 16), with a correlation $R$ value of 0.71 (51\% variance explained) for the smoothed series. The time series of vertical shear is not well correlated with GP, and

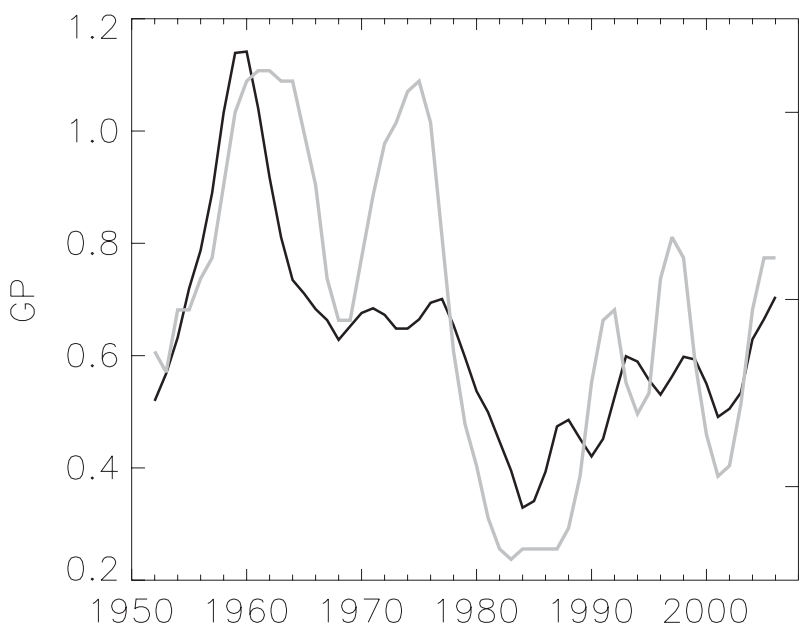

FIG. 16. Time series of seasonal Arabian Sea GP (black line) and storm counts (gray line) for the period 1950-2008. These smoothed time series are created by filtering the annual time series of each variable with a 5-yr low-pass filter. Annual time series is defined as in Fig. 15.

the SST time series is negatively correlated with the GP data ( $R$ value of -0.52 ). Thusly, changes in relative vorticity and midlevel moisture seem to dominate the longterm variability of Arabian GP.

A time series of 600-hPa relative humidity (Fig. 17) and specific humidity (not shown) are nearly indistinguishable ( $R$ value of 0.98 for the unsmoothed annual time series of each), while $600-\mathrm{hPa}$ temperature is not well correlated with relative humidity. It is plausible that dynamically forced reductions in midlevel moisture are driving the decline in relative humidity and therefore GP over the last $60 \mathrm{yr}$.

\section{Discussion and concluding remarks}

In this study we have attempted to understand the relationship between Arabian Sea cyclonic storms and their large-scale environment by analyzing observational and reanalysis data. Analysis of monthly cyclonic storm days and ACE indicate that starting in the early 1990s, there has been an increase in the numbers, duration, and intensity of Arabian Sea cyclones (Figs. 3 and 5), although data quality issues suggests these increases in storm metrics are likely nonphysical. There is a well-known, bimodal distribution to seasonal Arabian cyclonic storm activity (Figs. 2 and 4). We demonstrated how the seasonal cycle in activity is a function of the state of the coupled low-level winds and surface ocean temperature (Fig. 6) by presenting long-term monthly-mean maps of low-level winds and relative vorticity, vertical wind shear, and $200-\mathrm{hPa}$ winds, showing how these environmental features change together over the course of the cyclone 

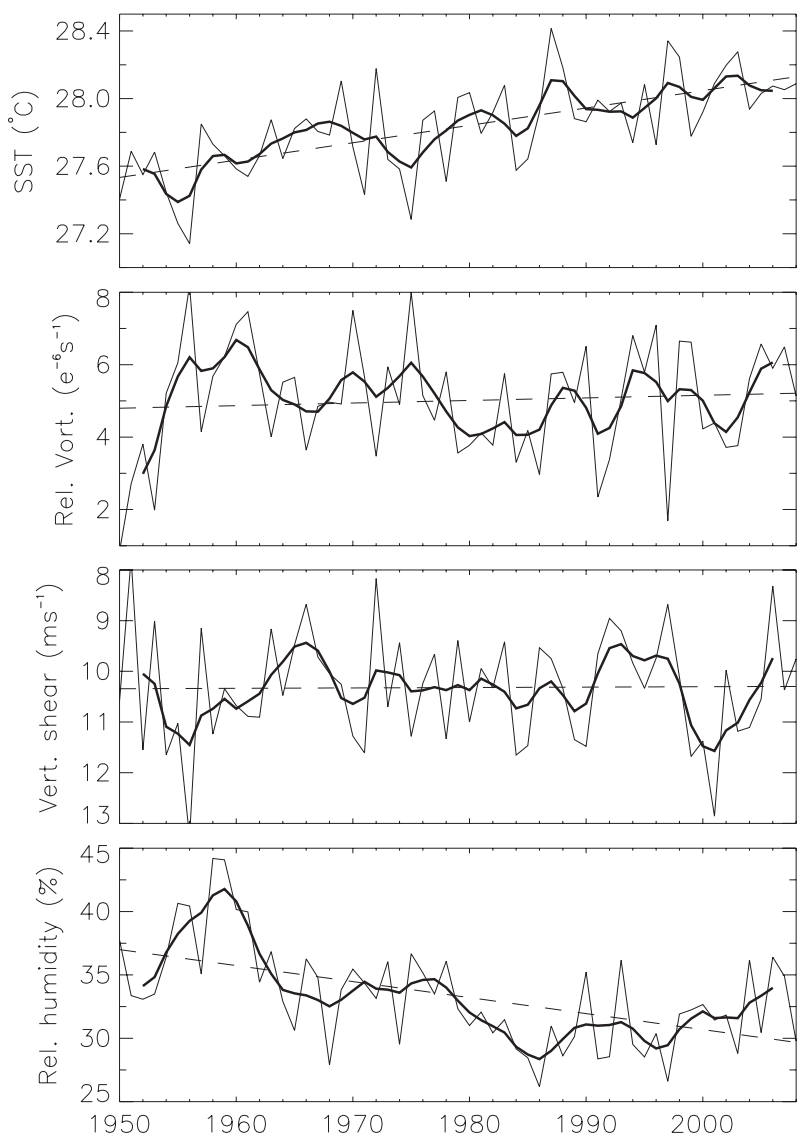

FIG. 17. Seasonal Arabian time series of (from top to bottom) SST, low-level vorticity, layer-mean vertical wind shear (note the inverse $y$ scale for vertical shear), and 600-hPa relative humidity. Description for individual time series plots as in Fig. 15.

season to establish regions over the Arabian Sea that are favorable for storm development (Figs. 8 and 9), consistent with earlier findings (Gray 1968).

We hypothesized that in addition to shaping the pattern of seasonal variability, year-to-year changes in large-scale features over the Arabian Sea also forced interannual variability in storm frequency. To test this we analyzed difference maps of SST, SLP, relative vorticity, vertical wind shear, 850 - and $200-\mathrm{hPa}$ vector winds, $600-\mathrm{hPa}$ relative humidity, and upper- and lower-level convergence, composited around storm counts for the three most active months (May, June, and November). These composite maps all suggest that large-scale features coherently organize themselves in such a way as to create an anomalous environment that is conducive to cyclonic storm activity. We found that May cyclogenesis events were associated with large-scale conditions, consistent with an early southwest monsoon onset (Fig. 10), while June storms were associated with conditions consistent with a delayed monsoon onset (Fig. 11). November storms were most clearly associated with sea level pressure anomalies over the Bay of Bengal, implying a preference for November storm formation in either the Arabian or the Bay of Bengal but not in both at the same time (Fig. 12; Table 2).

We used the genesis potential index as another way of understanding the relationship between Arabian tropical cyclones and the large-scale environment. Long-termmean GP fields all show positive GP anomalies in the areas of historical cyclogenesis (Fig. 13), supporting the hypothesis that over the course of the season, environmental features coherently organize themselves in such a way as to create regions suitable for cyclogenesis. Monthly GP difference maps, composited around cyclonic storm frequency generally show positive GP anomalies in the regions where storm genesis has taken place, supporting our hypothesis that year-to-year changes in large-scale environmental conditions force interannual variability Arabian storms (Fig. 14).

Since monthly GP fields reproduce the seasonal patterns of cyclogenesis, we analyzed a regional Arabian GP time series to determine if the time evolution of the GP is useful in understanding the time series of seasonal Arabian cyclonic storm days and ACE. Over the last $30 \mathrm{yr}$, seasonal Arabian GP has increased (Fig. 15), supporting a physical interpretation of the upward trends in storm metrics from the best track. However, when looking over the last $60 \mathrm{yr}$, seasonal Arabian GP was much higher during the late 1950s through the early 1960 s, and that recent values were below the mean. Surprisingly, seasonal mean GP was very well correlated with annual Arabian Sea storm counts from the historical record (Fig. 16). We looked at time series of GP constituent variables and found that most of the variance in the GP data (Fig. 15) can be explained by changes in relative humidity, and to a lesser degree changes in relative vorticity (Fig. 17).

GP values are large over the Persian Gulf from July through September (Fig. 13). Clearly no storm genesis could be expected over this relatively small body of water, and entrainment of dry desert air from the surrounding environment into any storm that may enter the gulf would overwhelm the effect of very warm water temperatures and climatologically low vertical shear (Fig. 9). However, it is interesting to speculate on the fate of a storm that would track into the Persian Gulf, especially since this nearly occurred in 2007 with super cyclonic storm Gonu.

The large-scale dynamics of the Indian Ocean and the southwest monsoon are complicated, owing to the coupled response to external forcing, such as the Southern Oscillation (e.g., Shukla and Paolino 1983), and the region's internal dynamics (Saji et al. 1999; Webster et al. 1999). We have attempted to compartmentalize the dynamics of the Arabian to simplify the analysis of factors 
influencing cyclonic storm development here. However, because of this simplification, we are neglecting the role of coupled equatorial processes, such as the equatorial Indian dipole (Saji et al. 1999; Webster et al. 1999), variability of the Seychelles-Chagos thermocline ridge (Vialard et al. 2009), and the influences of these processes on the strength and timing of Arabian low-level winds and coastal upwelling (Izumo et al. 2008). Here we also do not account for the effect of the MJO on the year-to-year variability of seasonal Arabian Sea tropical cyclone activity (Camargo et al. 2009). It is possible that considering the enhanced convective activity associated with one or more phases of the MJO, in conjunction with the large-scale ocean-atmosphere patterns associated with cyclogenesis we describe here, will help to paint a more complete picture of the environmental conditions associated with Arabian Sea storm activity.

The Arabian Sea is also a region with intense dust outbreaks that originate over either the Arabian Peninsula or the Pakistan-Afghanistan region (e.g., Evan et al. 2006). It is interesting to speculate on the possibility that dust outbreaks here may indirectly influence tropical cyclone activity in a manner similar to what has been proposed for African dust outbreaks and Atlantic hurricanes (Evan et al. 2008). Initial efforts to determine the importance of mineral aerosols on Arabian Sea SST, performed in a manner similar to those in Evan et al. (2009) for the Atlantic, imply that Arabian Sea SST is not sensitive to mineral aerosols via the aerosol direct effect (not shown). However, other work has suggested the dust outbreaks may alter the state of the southwest monsoon via the so-called elevated heat pump (Lau et al. 2009). If springtime dust outbreaks deposit mineral aerosols over snow- and ice-covered surfaces of the Himalayan foothills, the resulting reduction in albedo would provide an elevated heat source via the absorption of solar radiation by the aerosols, resulting in an upper-level warm-core anticyclone over northern Indian and enhanced monsoon flow (Lau et al. 2009). However, whether this proposed causal chain is robust is debatable, and any consequences on seasonal Arabian Sea tropical cyclone activity are not yet clear.

Acknowledgments. Partial support for this work was provided by a grant from Risk Prediction Initiative. We are grateful for correspondence with R. Murnane and R. Pappert. We thank Christopher Landsea and two anonymous reviewers for their comments on an earlier version of this paper.

\section{REFERENCES}

Bell, G. D., 2003: Atlantic hurricane season [in "State of the Climate in 2002"]. Bull. Amer. Meteor. Soc., 84, S19-S26.
Bister, M., and K. A. Emanuel, 2002a: Low frequency variability of tropical cyclone potential intensity 1 . Interannual to interdecadal variability. J. Geophys. Res., 107, 4801, doi:10.1029/ 2001JD000776.

, and _ 2002b: Low frequency variability of tropical cyclone potential intensity 2. Climatology for 1982-1995. J. Geophys. Res., 107, 4621, doi:10.1029/2001JD000780.

Camargo, S. J., K. A. Emanuel, and A. H. Sobel, 2007: Use of a genesis potential index to diagnose ENSO effects on tropical cyclone genesis. J. Climate, 20, 4819-4834.

, M. C. Wheeler, and A. H. Sobel, 2009: Diagnosis of the MJO modulation of tropical cyclogenesis using an empirical index. J. Atmos. Sci., 66, 3061-3074.

- A. H. Sobel, A. G. Barnston, and P. J. Klotzbach, 2010: The influence of natural climate variability on tropical cyclones, and seasonal forecasts of tropical cyclone activity. Global Perspectives on Tropical Cyclones: From Science to Mitigation, J. C. L. Chan and J. D. Kepert, Eds., World Scientific Series on Asia-Pacific Weather and Climate, Vol. 4, World Scientific Publishing, 325-360.

Chu, J.-H., C. R. Sampson, A. S. Levine, and E. Fukada, 2002: The Joint Typhoon Warning Center tropical cyclone best-tracks, 1945-2000. U.S. Naval Research Laboratory Rep. NRL/MR/ 7540-02-16, 22 pp.

Clark, C. O., J. E. Cole, and P. J. Webster, 2000: Indian Ocean SST and Indian summer rainfall: Predictive relationships and their decadal variability. J. Climate, 13, 2503-2519.

Dvorak, V. F., 1975: Tropical cyclone intensity analysis and forecasting from satellite imagery. Mon. Wea. Rev., 103, 420-430. , 1982: Tropical cyclone intensity analysis and forecasting from satellite visible or enhanced infrared imagery. NOAA National Environmental Satellite Service, Applications Laboratory Training Notes, $42 \mathrm{pp}$.

, 1984: Tropical cyclone intensity analysis using satellite data. NOAA Tech. Rep. 11, 45 pp.

_- 1995: Tropical clouds and cloud systems observed in satellite imagery: Tropical cyclones. Workbook Vol. 2, 359 pp. [Available from NOAA/NESDIS, 5200 Auth Rd., Washington, DC 20333.]

Elsner, J. B., J. P. Kossin, and T. H. Jagger, 2008: The increasing intensity of the strongest tropical cyclones. Nature, 455, 92-95.

Emanuel, K. A., 1988: The maximum intensity of hurricanes. J. Atmos. Sci., 45, 1143-1155.

- , and D. S. Nolan, 2004: Tropical cyclone activity and global climate. Proc. 26th Conf. on Hurricanes and Tropical Meteorology, Miami, FL, Amer. Meteor. Soc., 10A.2. [Available online at http://ams.confex.com/ams/26HURR/techprogram/ paper_75463.htm.]

Evan, A. T., A. K. Heidinger, and M. J. Pavolonis, 2006: Development of a new over-water advanced very high resolution radiometer dust detection algorithm. Int. J. Remote Sens., 27, 3903-3924.

- and Coauthors, 2008: Ocean temperature forcing by aerosols across the Atlantic tropical cyclone development region. Geochem. Geophys. Geosyst., 9, Q05V04, doi:10.1029/ 2007GC001774.

— D. J. Vimont, A. K. Heidinger, J. P. Kossin, and R. Bennartz, 2009: The role of aerosols in the evolution of tropical North Atlantic Ocean temperatures anomalies. Science, 324, 778-781.

Gray, W. M., 1968: Global view of the origin of tropical disturbances and storms. Mon. Wea. Rev., 96, 669-700.

Hart, R. E., R. N. Maue, and M. C. Watson, 2007: Estimating local memory of tropical cyclones through MPI anomaly evolution. Mon. Wea. Rev., 135, 3990-4005. 
Hastenrath, S., 1991: Climate Dynamics of the Tropics. Kluwer Academic Publishers, 486 pp.

Izumo, T., C. B. Montégut, J. J. Luo, S. K. Behera, S. Masson, and T. Yamagata, 2008: The role of the western Arabian Sea upwelling in Indian monsoon rainfall variability. J. Climate, 21, 5603-5623.

Joseph, P. V., J. K. Eischeid, and R. J. Pyle, 1994: Interannual variability of the onset of the Indian summer monsoon and its association with atmospheric features, El Niño, and sea surface temperature anomalies. J. Climate, 7, 81-105.

JTWC, 1998: Tropical Cyclone 03A. 1998 annual tropical cyclone report, JTWC Rep., 111-113.

— 2007: Section 3: Detailed cyclone reviews: TC 02A (Gonu). 2007 annual tropical cyclone report, JTWC Rep., 62-64.

Kalnay, E., and Coauthors, 1996: The NCEP/NCAR 40-Year Reanalysis Project. Bull. Amer. Meteor. Soc., 77, 437-471.

Knapp, K. R., and J. P. Kossin, 2007: A new global tropical cyclone data set from ISCCP B1 geostationary satellite observations. J. Appl. Remote Sens., 1, 013505, doi:10.1117/1.2712816.

— M. C. Kruk, D. H. Levinson, H. J. Diamond, and C. J. Neumann, 2010: The International Best Track Archive for Climate Stewardship (IBTrACS): Unifying tropical cyclone data. Bull. Amer. Meteor. Soc., 91, 363-376.

Kossin, J. P., K. R. Knapp, D. J. Vimont, R. J. Murnane, and B. A. Harper, 2007: A globally consistent reanalysis of hurricane variability and trends. Geophys. Res. Lett., 34, L04815, doi:10.1029/2006GL028836.

Kumar, K., B. Rajagopalan, M. Hoerling, G. Bates, and M. Cane, 2006: Unraveling the mystery of Indian monsoon failure during El Niño. Science, 314, 115-119.

Lander, M. A., and C. P. Guard, 1998: A look at global tropical cyclone activity during 1995: Contrasting high Atlantic activity with low activity in other basins. Mon. Wea. Rev., 126, 11631173.

Landsea, C. W., B. A. Harper, K. Hoarau, and J. A. Knaff, 2006: Can we detect trends in extreme tropical cyclones? Science, 313, 452-454.

Lau, K. M., K. M. Kim, C. Hsu, and B. Holben, 2009: Possible influences of air pollution, dust and sandstorms on the Indian monsoon. WMO Bull., 58, 22-30.
Lee, C. S., R. Edson, and W. M. Gray, 1989: Some large-scale characteristics associated with tropical cyclone development in the North Indian Ocean during FGGE. Mon. Wea. Rev., 117, 407-426.

Rayner, N. A., D. E. Parker, E. B. Horton, C. K. Folland, L. V. Alexander, D. P. Rowell, E. C. Kent, and A. Kaplan, 2003: Global analyses of sea surface temperature, sea ice, and night marine air temperature since the late nineteenth century. J. Geophys. Res., 108, 4407, doi:10.1029/2002JD002670.

Reynolds, R. W., N. A. Rayner, T. M. Smith, D. C. Stokes, and W. Wang, 2002: An improved in situ and satellite SST analysis for climate. J. Climate, 15, 1609-1625.

Saji, N. H., B. N. Goswami, P. N. Vinayachandran, and T. Yamagata, 1999: A dipole mode in the tropical Indian Ocean. Nature, 401, 360-363.

Shukla, J., and D. A. Paolino, 1983: The Southern Oscillation and long-range forecasting of the summer monsoon rainfall over India. Mon. Wea. Rev., 111, 1830-1837.

Singh, O. P., T. M. A. Khan, and M. S. Rahman, 2000: Changes in the frequency of tropical cyclones over the North Indian Ocean. Meteor. Atmos. Phys., 75, 11-20.

Swanson, K. L., 2008: False causality between Atlantic hurricane activity fluctuations and seasonal lower atmospheric wind anomalies. Geophys. Res. Lett., 35, L18807, doi:10.1029/2008GL034469.

Torrence, C., and P. J. Webster, 1999: Interdecadal changes in the ENSO-monsoon system. J. Climate, 12, 2679-2690.

Trenberth, K. E., 1997: The definition of El Niño. Bull. Amer Meteor. Soc., 78, 2771-2777.

Vialard, J., and Coauthors, 2009: Cirene: Air-sea interactions in the Seychelles-Chagos thermocline ridge region. Bull. Amer. Meteor. Soc., 90, 45-61.

Webster, P. J., A. M. Moore, J. P. Loschnig, and R. R. Leben, 1999: Coupled ocean-atmosphere dynamics in the Indian Ocean during 1997-98. Nature, 401, 356-360.

Wheeler, M. C., and H. H. Hendon, 2004: An all-season real-time multivariate MJO index: Development of an index for monitoring and prediction. Mon. Wea. Rev., 132, 1917-1932.

WHO, 2009: WRO Yemen situation report No. 3: Heavy flooding in Yemen, October 27, 2008, WHO Rep., 2 pp. [Available online at http://www.emro.who.int/eha/PDF/yemfloods_sitrep_3.pdf.] 